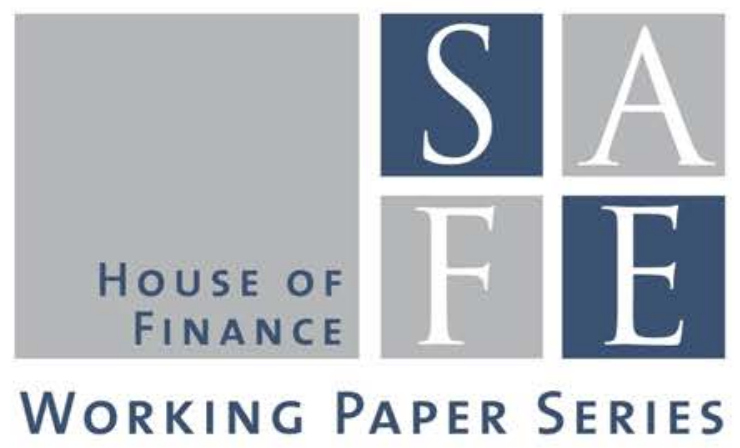

Christoph Hambel - Holger Kraft - Lorenz Schendel - Mogens Steffensen

\title{
Life Insurance Demand under Health Shock Risk
}

SAFE Working Paper No. 40

SAFE I Sustainable Architecture for Finance in Europe A cooperation of the Center for Financial Studies and Goethe University Frankfurt 


\section{Non-Technical Summary}

We analyze a family's term life insurance demand in a life cycle portfolio choice model. A major source of risk for a family is the early death of the sole wage earner. To hedge this, the family in our model can contract a term life insurance. Most existing papers studying the life insurance demand consider short term contracts that can be bought or sold continuously which ensures an optimal insurance holding at each point in time. This simplification might crucially affect the results. Therefore, we focus on a model where the family can choose between different long-term contracts that differ with respect to their insurance sum. The annual insurance premium includes fees for administrative costs and transaction costs. A belated change of the insurance is costly for the family and only possible as long as the insured person is younger than a specific age and healthy. The wage earner faces stochastic mortality risk with a jump component that we interpret as critical illness. Once the agent suffers from a critical illness, the family cannot change the insurance contract any more, the income of the family reduces, and the mortality risk increases. If the wage earner dies before the maturity of the insurance contract, the remaining family members receive a single, fixed payment of the insurance company. We use a German life table to calibrate the mortality process, German cancer data to calibrate the critical illness shock and data of the German life insurance industry to calibrate the insurance fees. The insurance premiums are calculated such that the contracts are actuarially fair.

The realistically modeled insurance induces new qualitative effects that are important for the optimal decisions over the life cycle. The long-term insurance contract amplifies the effect of negative labor income shocks, since in the undesired case of a negative labor income shock a premature termination of the contract or a reduction of the insurance sum leads to additional losses. In an already bad state, the family has problems to make the premium payments. Families with a lower income volatility have a significantly higher insurance demand. The amplifying effect also reduces the insurance demand of families that are more risk averse. In general, the families increase insurance protection over the life cycle. The long term contract design effect fades away as agents get older, since the contract duration and human wealth uncertainty reduce. Most importantly, young families do not buy any long-term term life insurance. If an older agent suddenly dies, the accumulated financial wealth and contracted insurance ensures that the surviving family member can maintain their consumption level, although consumption growth is reduced. By contrast, an unexpected death in younger years leads to severe problems for the family.

Our results are robust to adding short-term insurance, annuities, or health insurance. For instance, if families have also access to short-term insurance, they buy these contracts at a young age without demanding long-term insurance. This decision leaves the possibility open that a health shock prevents them from renewing short-term contracts. In this case, the family might suffer financial hardship when the wage earner eventually dies. To avoid lifetime poverty of the remaining family members, a social security could mitigate those problems by making transfer payments. 


\section{Life Insurance Demand under Health Shock Risk}

This version: June 3, 2015

\section{Christoph Hambel}

Goethe University, Faculty of Economics and Business Administration,

Frankfurt am Main, Germany,

email: christoph.hambel@finance.uni-frankfurt.de

\section{Holger Kraft}

Goethe University, Faculty of Economics and Business Administration, Frankfurt am Main, Germany, email: holgerkraft@finance.uni-frankfurt.de

\section{Lorenz S. Schendel}

Goethe University, Faculty of Economics and Business Administration, Frankfurt am Main, Germany, email: schendel@safe.uni-frankfurt.de

\section{Mogens Steffensen}

University of Copenhagen, Department of Mathematical Sciences, Copenhagen, Denmark, email:mogens@math.ku.dk

Acknowledgements: Christoph Hambel, Holger Kraft and Lorenz Schendel gratefully acknowledge research and financial support from the Center of Excellence SAFE, funded by the State of Hessen initiative for research LOEWE. Holger Kraft gratefully acknowledges financial support by Deutsche Forschungsgemeinschaft (DFG). The authors thank the Frankfurt Cloud for access to high-performance virtual servers. 


\section{Life Insurance Demand under Health Shock Risk}

ABstract: This paper studies the life cycle consumption-investment-insurance problem of a family. The wage earner faces the risk of a health shock that significantly increases his probability of dying. The family can buy long-term life insurance that can only be revised at significant costs, which makes insurance decisions sticky. Furthermore, a revision is only possible as long as the insured person is healthy. A second important feature of our model is that the labor income of the wage earner is unspanned. We document that the combination of unspanned labor income and the stickiness of insurance decisions reduces the long-term insurance demand significantly. This is because an income shock induces the need to reduce the insurance coverage, since premia become less affordable. Since such a reduction is costly and families anticipate these potential costs, they buy less protection at all ages. In particular, young families stay away from long-term life insurance markets altogether. Our results are robust to adding short-term life insurance, annuities and health insurance.

KeYwords: Health shocks, Portfolio choice, Term life insurance, Mortality risk, Labor income risk

JEL-Classification: D14, D91, G11, G22 


\section{Introduction}

For most households, labor income is the essential source to finance lifetime consumption. Therefore, a potential income loss following an early death of the wage earner is a crucial risk. Consequently, a life insurance is of special importance to hedge future consumption of the remaining family members. Following Richard (1975) most studies simplify the insurance decision by including an instantaneous term insurance contract. However, in practice buying life insurance usually involves a long-term commitment and later changes are costly. Furthermore, health checks prevent agents from contracting an insurance if they already have a critical illness. As benchmark scenario, we thus study a life cycle problem where a family has access to longterm life insurance that can only be bought or sold at realistic lump-sum costs. ${ }^{1}$ In a second step, we demonstrate that our results also hold if we add annuities or short-term life insurance contracts.

Our model involves several relevant features: The family receives unspanned labor income earned by the head of the household and faces short-sale constraints that bind its stock demand, especially at young ages. Furthermore, the wage earner faces the risk of suffering from a health shock that we interpret as critical illness. After such a health shock the family has no access to the insurance market any more, i.e. cannot buy new insurance or change/extend existing contracts. Additionally, the wage earner's probability of dying increases significantly. We calibrate the health shock and mortality process to cancer and mortality data.

The combination of these features (long-term insurance contracts, transaction costs, unspanned labor income, short-sale constraints, health shocks) distinguishes our model from the related literature discussed in Section 2. This combination generates interesting qualitative effects that are important for the optimal decisions of the family over the life cycle: The long-term nature of the insurance contract amplifies the effect of negative labor income shocks, since in the undesired case of a negative labor income shock a premature termination of the contract or a reduction of the insurance sum leads to additional losses. In an already bad state, the family might be worse off due to the stickiness of the insurance contract. Therefore, families

\footnotetext{
${ }^{1}$ Formally, we model the insurance decision as an impulse control problem.
} 
with higher income uncertainty have significantly lower insurance demands.

Most importantly, we find that younger families (head of household less than 30 years old) optimally stay away from long-term life insurance markets. Therefore, an unexpected death in younger years can lead to severe problems for the family. Our findings significantly differ from the results in frameworks that model life insurance decisions via an instantaneous contract instead of a long-term contract as in the benchmark case of our paper. In these frameworks, the theoretically optimal participation rates are typically higher. We address this point by also considering a situation where families have access to short-term life insurance contracts as well (see Section 6). In this case, families buy short-term contracts at young ages. However, the demand for long-term contracts is essentially unaffected, which shows the robustness of our benchmark results. Consequently, young families leave the risk uninsured that the head of the household suffers from a health shock so that the short-term contract cannot be extended.

Furthermore, we find that it is optimal for families to increase long-term insurance protection over the life cycle. This is because the long-term contract design becomes less relevant as agents get older, since the contract duration and the uncertainty about human wealth goes down. Therefore, if an older wage earner suddenly dies, the accumulated financial wealth and existing insurance contracts ensure that surviving family members can maintain their standard of living, although consumption growth must be reduced. To summarize, our results suggest that a high level of income, a high labor income volatility, large fees imposed by insurance companies and the presence of health shocks reduce the long-term insurance demand of a family. Notice that the optimal total insurance demand (long-term and short-term) is hump-shaped if we add short-term contracts, which is qualitatively in line with empirical evidence.

Recently, a large literature has discussed the driving factors for surrender behavior, including Fang and Kung (2012), Fier and Liebenberg (2013), and Gottlieb and Smetters (2014). These authors document the dominating role of income shocks in encouraging people to surrender their life insurance policies. Gottlieb and Smetters (2012) argue that empirically households do not pay careful attention to the stickiness of long-term insurance products and to the unspanned nature of income, also due to health shock risk. Consequently, households may end up with 
suboptimally high insurance protection. Liquidity needs may force them to surrender. Our results show that in a neoclassical model households have a low surrender rate since they rationally anticipate their future liquidity demands. This might explain why Gottlieb and Smetters (2012) provide a behavioral explanation using narrow framing.

The remainder of the paper is organized as follows. Section 2 provides an overview of the related literature. Section 3 introduces the model setup. Section 4 presents the calibration. Section 5 discusses our benchmark results. Section 6 study insurance market involving annuities, shortterm insurance or health insurance. Section 7 provides robustness checks. Section 8 concludes. An appendix contains additional robustness checks.

\section{$2 \quad$ Related Literature}

The modern portfolio optimization literature starts with Merton (1969) and Merton (1971). In discrete time, Cocco, Gomes, and Maenhout (2005) numerically solve a realistically calibrated life cycle model with deterministic mortality risk. One of their main objects is to study the effect of unspanned labor income that is calibrated to US data. Munk and Sørensen (2010) solve a realistically calibrated life cycle model in continuous time with unspanned labor income, but without mortality risk. Their main focus is on analyzing the effect of unspanned labor income and a stochastic riskfree rate on consumption-investment decisions. They adapt the labor income calibration results from Cocco, Gomes, and Maenhout (2005) to a continuous-time framework and find that unspanned labor income significantly effects consumption-investment decisions.

Merton (1975) points out the importance of the risk of dying as a source of risk. Campbell (1980) studies the corresponding optimization problem. He considers a two-period model and introduces an insurance market to allow a family to hedge the risk that the wage earner dies. Analytically, he derives the optimal demand for insurance. Yaari (1965) analyzes the consumption decision of an agent when faced with longevity risk. Richard (1975) analytically solves a life cycle problem with deterministic labor income and a continuous instantaneous term insurance 
decision. He allows an uncertain time of death with deterministic distribution. Simple forms of an actuarially fair one-period life insurance contract are still widely used in the portfolio optimization literature. Pliska and Ye (2007) mathematically extend the model and analyze the effect of parameter choice on the life insurance demand. Closely related to our work is the paper Huang, Milevsky, and Wang (2008), who also consider the consumption-investment and life-insurance decision of a family with CRRA utility. They focus on the correlation between labor income and asset returns. Their main results are that life-insurance demand is insensitive to changing risk aversion and highly depends on labor income volatility. As the previous literature, they also model life insurance via a short-term contract and do not consider health shocks or stochastic mortality risk.

Recent papers building on the work of Richard (1975) use a continuous-time finite-state Markov chain approach to solve life cycle portfolio problems with insurance decisions analytically. Kraft and Steffensen (2008) focus on the consumption and insurance decision of a single person that faces the risk of dying and disability. Bruhn and Steffensen (2011) consider the consumptioninvestment and insurance decision of a two- and multi-person household. This strand of literature is able to provides analytical solutions of optimal insurance decisions, but relies on the assumptions that markets are complete and thus is not able to capture crucial realistic features such as unspanned labor income risk.

There are also recent papers studying life cycle problems of families that face mortality risk and can insure themselves via life insurance contracts. Love (2010) focuses on the effect of demographic shocks. In his model, the agent can exogenously get married, get divorced or have children. We adapt his calibration approach to capture the impact of the family size on the utility from consumption. His model involves a simple one-period term life insurance. Hubener, Maurer, and Rogalla (2014) analyze the optimal life insurance demand of retired couples. They model husband and wife via two separate mortality processes, but do not allow for changes in the family status (e.g. divorce). Since they consider only the retirement phase, they especially focus on annuities and disregard labor income. Hong and Ríos-Rull (2012) infer how individuals value consumption in different demographic stages using life insurance holdings by age, sex, 
and marital status. In particular, they estimate a consumption equivalence scale parameter. There are also papers on life cycle problems with stochastic mortality risk. In a discrete-time setting, Cocco and Gomes (2012) include stochastic mortality risk in a realistically calibrated life cycle model which they solve numerically. They capture mortality risk by a Lee-Carter type model. The agent can invest in a riskless bond and in a longevity bond that is correlated with shocks in mortality rates. Furthermore, they allow the agent to choose the retirement date endogenously. Huang, Milevsky, and Salisbury (2012) analyze optimal consumption decisions analytically and compare results from a Yaari type model with a model allowing for stochastic mortality risk. In contrast to our paper, stochastic mortality risk is modeled as a geometric Brownian motion. Koijen, Van Nieuwerburgh, and Yogo (2013) consider a life cycle problem where the probability of dying can have unsystematic jumps. They develop risk measures for life and health insurance products that pool the effects of several insurance products. In a discrete-time setting, they calculate the corresponding optimal results for their risk measures. They also compare the model implied risk measures with empirically derived values where their focus on agents that are older than 50 years. Their model also involves critical illness jumps. In contrast to our paper, they focus on the insurance implications, but do not consider unspanned labor income or stock market risk. Finally, Hugonnier, Pelgrin, and St-Amour (2013) study the interplay of financial and health-related choices. They also provide conditions under which both decisions can be made separately.

\section{Model Setup}

In this section, we present the model setup and describe the optimization problem of the family.

Financial Assets The family (syn. agent) can invest into two financial assets, but faces short-sale constraints. The assets are a risky stock (index) $S$ and a riskfree bond $B$. The 
riskfree rate is denoted by $r$. The dynamics are given by

$$
\begin{aligned}
d S_{t} & =S_{t}\left[\left(r+\sigma_{S} \lambda\right) d t+\sigma_{S} d W_{t}^{S}\right] \\
d B_{t} & =B_{t} r d t
\end{aligned}
$$

with a constant market price of risk $\lambda$ and a stock market volatility of $\sigma_{S}$. The process $W^{S}=$ $\left(W_{t}^{S}\right)$ is a standard Brownian motion.

Biometric Risk The sole wage earner faces the risk of a health shock (e.g. cancer) and of a death shock. The state variable $H$ defined by

$$
H_{t}= \begin{cases}1 & \text { alive and healthy at } t \\ 2 & \text { alive but unhealthy at } t \\ 3 & \text { dead at } t\end{cases}
$$

captures the current status of the wage earner. The random age of death is denoted by $\tau^{D}$ and is modeled as doubly stochastic stopping time with intensity $\pi(t, H)$, the so-called hazard rate of death, where $\pi(t, 3)=0$. Formally, $\tau^{D}$ is the time of the first jump of the jump process $N^{D}=\left(N_{t}^{D}\right)$. As long as $H_{t}=1$, the health shock jump process $N^{H}=\left(N_{t}^{H}\right)$ has a deterministic intensity $\kappa(t)$. The health shock is permanent so that agents cannot recover again. Unhealthy agents cannot face another health shock. ${ }^{2}$ The time of a health shock is denoted by $\tau^{H}$. If the agent does not experience a health shock during his lifetime, then $\tau^{H}$ is infinity.

Unspanned Labor Income The family receives an uncertain income stream denoted by $Y$. Its dynamics are influenced by the health status and age of the wage earner and are given by

$$
\begin{gathered}
d Y_{t}=\mathbb{1}_{\left\{H_{t}=1,2\right\}} Y_{t}\left(\mu_{Y}(t) d t+\sigma_{Y}(t)\left(\rho(t) d W_{t}^{S}+\sqrt{1-\rho(t)^{2}} d W_{t}^{Y}\right)\right)+\mathbb{1}_{\left\{H_{t^{-}}=1\right\}} Y_{t^{-}}\left(p^{1,2}(t)-1\right) d N_{t}^{H} \\
+\mathbb{1}_{\left\{H_{t^{-}}=1\right\}} Y_{t^{-}}\left(p^{1,3}(t)-1\right) d N_{t}^{D}+\mathbb{1}_{\left\{H_{t^{-}}=2\right\}} Y_{t^{-}}\left(p^{2,3}(t)-1\right) d N_{t}^{D}
\end{gathered}
$$

where $W^{Y}=\left(W_{t}^{Y}\right)$ is a standard Brownian motion, independent of $W^{S}$. This income stream is unspanned for two reasons: First, the Brownian motion $W^{Y}$ cannot be hedged in the financial market. Second, the health shock $N^{H}$ cannot be fully insured.

\footnotetext{
${ }^{2}$ Our results hardly change if we allow for more than one health shock.
} 
Furthermore, $p^{i, j}$ is the fraction of income that remains after a jump from state $i$ to state $j$. We assume that the agent retires at the prespecified date $T_{R}$. The income process has a drift of $\mu_{Y}$, a volatility of $\sigma_{Y}$ and is correlated with the stock via $\rho$. Before retirement, the family's income is interpreted as labor income, whereas it is a pension after the retirement date. After the death of the wage earner, the income stream can be interpreted as widow's pension indexed by the salary upon death. If a critical illness shock occurs, the decreased income can be interpreted in the sense that the wage earner is forced to reduce work effort. ${ }^{3}$ Alternatively, it can be interpreted as a transfer income that the family receives from the government.

Long-term Life Insurance The family can buy a long-term life insurance to hedge the potential income loss resulting from the mortality risk of the wage earner. While the insurance contract is active, the insurance company pays the family a fixed payment $I$ if the wage earner dies. The insurance offers a fixed set of contracts with specific payouts. The set of offered contracts is denoted by

$$
\mathcal{I}=\{0,50000,100000,150000,200000,300000,500000,750000,1000000,2000000\}
$$

The family must pay a constant insurance premium $\iota(I)$ as long as the contract is active. When the agent changes the insurance sum of the contract, a lump-sum payment $\eta$ is due. This payment takes the previous insurance sum, the new insurance sum and the age of the agent that determines the mortality pattern into account. The lump-sum payment ensures an actuarially fair new contract, but it also involves a fee. The contract can be changed as long as the wage earner is healthy and younger than $T_{C}$. The insurance contract expires at $\min \left(\tau^{D}, T_{I}\right)$, i.e. at the death of the insured person or at the maturity of the contract, $T_{I}$. In the first case, the insurance pays the insurance sum $I$, in the second case the insurance pays nothing. We assume that $T_{C}<T_{I}$, i.e. after $T_{I}$ there is no insurance available any more.

Technically, the insurance decision can be characterized by an impulse control problem. The family chooses the intervention times $\zeta_{i}, i \in \mathbb{N}$, and the intervention actions $\omega_{i}, i \in \mathbb{N}$. The intervention can take place at time $\zeta_{i}$ if the wage earner is alive $\left(\zeta_{i}<\tau^{D}\right)$, healthy $\left(H_{\zeta_{i}}=1\right)$,

\footnotetext{
${ }^{3}$ In Section 6 we also analyze the effect of additional medical expenses that are triggered by a health shock.
} 
and in the insurance market $\left(\zeta_{i} \leq T_{C}\right)$. A feasible intervention action requires that $\omega_{i}$ is chosen such that the new insurance sum is in the set of offered contracts, $I_{\zeta_{i}} \in \mathcal{I}$. We denote the set of possible interventions at $\zeta_{i}$ by

$$
\mathcal{I}_{\zeta_{i}}=\left\{0-I_{\zeta_{i}^{-}}, 50000-I_{\zeta_{i}^{-}}, \ldots, 2000000-I_{\zeta_{i}^{-}}\right\}
$$

Formally, the above statement can be expressed by the condition $\omega_{i} \in \mathcal{I}_{\zeta_{i}}$. At an intervention time, the family must pay the lump-sum payment $\eta_{I}\left(\zeta_{i}, \omega_{i}, I_{\zeta_{i}}\right)$ that is a correction payment which makes the insurance contract actuarially fair, but additionally involves a fee. A detailed description is postponed to Section 4, see equation (4.4). Following the intervention, the family pays the new annual premium $\iota\left(I_{\zeta_{i}}\right)$ to maintain insurance protection until $\min \left(\tau^{D}, T_{I}\right)$.

Reducing the insurance sum can be thought of as partial surrendering. Reducing the insurance sum to zero corresponds to full surrendering. Controlling the insurance sum is only allowed when the wage earner is healthy since the insurance contract is priced as a long-term contract on that basis. One could in principle work with access to surrendering as unhealthy, but such a demand would be negligible since the agent then holds a relatively cheap insurance contract. So by product pricing, all reclassification risk is borne by the insurance company and therefore limits the agents controllability over the contract sum. In Section 6 we study the effects on our conclusion from access to short-term life insurance while healthy. For that product the reclassification risk is borne by the policy holder. See also Gottlieb and Smetters (2014) for the understanding of reclassification risk in connection with surrender options.

Preferences The family has a fixed time horizon $T$ and a power utility function given by

$$
u(x, H)=\frac{\left(\frac{x}{\phi_{H}}\right)^{1-\gamma}}{1-\gamma}
$$

with relative risk aversion $\gamma$. Here $\phi_{H}$ is a consumption scaling term that depends on the family size and for instance captures that two persons do not need twice as much consumption as a single person for the same utility level. ${ }^{4}$ The family maximizes expected utility from

\footnotetext{
${ }^{4}$ Preferences with a consumption scaling parameter are used by Love (2010) and Hubener, Maurer, and Rogalla (2014).
} 
intermediate consumption and terminal wealth given by

$$
\mathrm{E}_{t, x, y, I, H}\left[\int_{t}^{T} \mathrm{e}^{-\delta(u-t)} \frac{\left(\frac{c_{u}}{\phi_{H_{u}}}\right)^{1-\gamma}}{1-\gamma} d u+\varepsilon \mathrm{e}^{-\delta(T-t)} \frac{X_{T}^{1-\gamma}}{1-\gamma}\right]
$$

with time preference rate $\delta$ and financial wealth $X$. The constant $\varepsilon$ specifies the importance of the bequest motive. ${ }^{5}$

Financial Wealth Dynamics The family chooses consumption $c$ and the fraction $\theta$ invested in the risky asset. As long as the wage earner is healthy and young, the family also optimizes over the insurance sum via the impulse control strategy $\left(\zeta_{i}, \omega_{i}\right), i \in \mathbb{N}$. The wealth dynamics follow

$$
\begin{aligned}
d X_{t}= & X_{t}\left[\left(r+\theta_{t} \lambda \sigma_{S}\right) d t+\theta_{t} \sigma_{S} d W_{t}^{S}\right]+\left[Y_{t}-c_{t}-\mathbb{1}_{\left\{A_{t}=1,2 \wedge t<T_{I}\right\}} \iota\left(I_{t}\right)\right] d t \\
& +\mathbb{1}_{\left\{A_{t^{-}}=1,2 \wedge t<T_{I}\right\}} I_{t^{-}} d N_{t}^{D}, \\
X_{\zeta_{i}}= & X_{\zeta_{i}^{-}}-\eta\left(\zeta_{i}, \omega_{i}, I_{\zeta_{i}}\right) .
\end{aligned}
$$

Optimization Problem As stated above, the family optimizes expected utility from intermediate consumption and terminal wealth. The optimization problem is characterized by several state variables: financial wealth $x$, labor income $y$, the health status of the wage earner $H$ and the current insurance choice $I$. The control variables are the consumption rate $c$, the proportion of wealth $\theta$ invested in risky assets, and the impulse control strategy for the insurance decision $\left(\zeta_{i}, \omega_{i}\right), i \in \mathbb{N}$. At time $t=0$ the wage earner is assumed to be 20 years old. The optimization problem is then given by

$$
\begin{aligned}
& \max _{\left\{c_{s}, \theta_{s}\right\}_{s \in[0, T)},\left\{\left(\zeta_{i}, \omega_{i}\right)\right\}_{i \in \mathbb{N}}} \mathrm{E}_{0, x, y, I, H}\left[\int_{0}^{T} \mathrm{e}^{-\delta u} \frac{\left(\frac{c_{u}}{\phi_{H_{u}}}\right)^{1-\gamma}}{1-\gamma} d u+\varepsilon \mathrm{e}^{-\delta T} \frac{X_{T}^{1-\gamma}}{1-\gamma}\right] \\
& \text { s.t. } \quad d X_{t}=X_{t}\left[\left(r+\theta_{t} \lambda \sigma_{S}\right) d t+\theta_{t} \sigma_{S} d W_{t}^{S}\right]+\left[Y_{t}-c_{t}-\mathbb{1}_{\left\{A_{t}=1,2 \wedge t<T_{I}\right\}} \iota\left(I_{t}\right)\right] d t \\
& \quad+\mathbb{1}_{\left\{H_{t^{-}}=1,2 \wedge t<T_{I}\right\}} I_{t^{-}} d N_{t}^{D}, \\
& X_{\zeta_{i}}=X_{\zeta_{i}^{-}}-\eta\left(\zeta_{i}, \omega_{i}, I_{\zeta_{i}}\right),
\end{aligned}
$$

\footnotetext{
${ }^{5}$ We analyze the effects of luxury bequests in Section 7.
} 
where we impose short-sale constraints, i.e. $\theta_{t} \in[0,1]$, and consider admissible strategies, which in particular requires $X_{t} \geq 0 .{ }^{6}$ The value function (indirect utility function) is defined by

$$
J(t, x, y, I, H)=\sup _{\left\{c_{s}, \theta_{s}\right\}_{s \in[t, T)},\left\{\left(\zeta_{i}, \omega_{i}\right)\right\}_{i \in \mathbb{N}}} \mathrm{E}_{t, x, y, I, H}\left[\int_{t}^{T} \mathrm{e}^{-\delta(u-t)} \frac{\left(\frac{c_{u}}{\phi_{H_{u}}}\right)^{1-\gamma}}{1-\gamma} d u+\varepsilon \mathrm{e}^{-\delta(T-t)} \frac{X_{T}^{1-\gamma}}{1-\gamma}\right] .
$$

We split the problem into its impulse control and stochastic control part. Given no intervention at $t$, but optimal impulse control afterwards, the value function is denoted by

$J^{*}(t, x, y, I, H)=\sup _{\left\{c_{s}, \theta_{s}\right\}_{s \in[t, T)},\left\{\left(\zeta_{i} \mid \zeta_{i} \neq t, \omega_{i}\right)\right\}_{i \in \mathbb{N}}} \mathrm{E}_{t, x, y, I, H}\left[\int_{t}^{T} \mathrm{e}^{-\delta(u-t)} \frac{\left(\frac{c_{u}}{\phi_{H_{u}}}\right)^{1-\gamma}}{1-\gamma} d u+\varepsilon \mathrm{e}^{-\delta(T-t)} \frac{X_{T}^{1-\gamma}}{1-\gamma}\right]$.

In this case, the optimization problem reduces to a stochastic control problem. The corresponding Hamilton-Jacobi-Bellman equation (HJB) is given by

$$
\begin{aligned}
\delta J^{*}=\sup _{c, \theta} & \left\{\frac{\left(\frac{c}{\phi_{H}}\right)^{1-\gamma}}{1-\gamma}+J_{t}^{*}\right. \\
& +J_{x}^{*}\left[x\left(r+\theta \lambda \sigma_{S}\right)+y-c-\mathbb{1}_{\left\{A=1,2 \wedge t<T_{I}\right\}} \iota(I)\right] \\
& +\frac{1}{2} J_{x x}^{*} x^{2} \theta^{2} \sigma_{S}^{2}+\mathbb{1}_{\{A=1,2\}}\left[J_{y}^{*} y \mu_{Y}(t)+\frac{1}{2} J_{y y}^{*} y^{2} \sigma_{Y}(t)^{2}+J_{x y}^{*} x y \sigma_{S} \sigma_{Y}(t) \rho(t) \theta\right] \\
& +\mathbb{1}_{\{H=1\}} \kappa(t)\left[J^{*}\left(t, x, p^{1,2}(t) y, I, 2\right)-J^{*}(t, x, y, I, 1)\right] \\
& +\mathbb{1}_{\{A=1\}} \pi(t, H)\left[J^{*}\left(t, x+\mathbb{1}_{\left\{t \leq T_{I}\right\}} I, p^{1,3}(t) y, 0,3\right)-J^{*}(t, x, y, I, 1)\right] \\
& \left.+\mathbb{1}_{\{A=2\}} \pi(t, H)\left[J^{*}\left(t, x+\mathbb{1}_{\left\{t \leq T_{I}\right\}} I, p^{2,3}(t) y, 0,3\right)-J^{*}(t, x, y, I, 2)\right]\right\}
\end{aligned}
$$

with terminal condition $J^{*}(T, x, y, I, H)=\varepsilon \frac{x^{1-\gamma}}{1-\gamma}$. Here subscripts on $J$ denote partial derivatives. Finally, we calculate the value function $J$ by maximizing $J^{*}$ over all possible interventions at $\zeta_{i}=t$ :

$$
J(t, x, y, I, H)=\sup _{\omega_{i} \in \mathcal{I}_{\zeta_{i}}}\left\{J^{*}\left(t, x-\eta\left(\zeta_{i}, \omega_{i}, I_{\zeta_{i}}\right), y, I+\omega_{i}, H\right)\right\} .
$$

\footnotetext{
${ }^{6}$ Since income is not bounded away from zero and the family has a bequest motive, the latter condition is automatically satisfied.
} 
Note that in the case of $\omega_{i}=0$ we have a continuation strategy, i.e. the family decides to keep its insurance decision. If this is optimal, then $J(t, x, y, I, H)=J^{*}(t, x, y, I, H)$. Consequently, there is no lump-sum payment, since we are in the no transaction region and $\eta\left(\zeta_{i}, 0, I_{\zeta_{i}}\right)=0$.

\section{Calibration}

This section describes the model calibration that is also summarized in Table 1.

\section{[INSERT TABLE 1 ABOUT HERE]}

Financial Assets We use standard values for the stock market drift $\left(\mu_{S}=0.06\right)$, the stock market volatility $\left(\sigma_{S}=0.2\right)$ and the riskfree rate $(r=0.02)$ that are similar to the values used by Cocco, Gomes, and Maenhout (2005) or Munk and Sørensen (2010), among others.

Biometric Risk Considering mortality risk, we use a Gompertz mortality model with constant parameters $x, m, b$ for the healthy agent and increase the hazard rate of death by a constant term $k_{1}$ and an age-dependent term $k_{2}$ if the agent becomes unhealthy

$$
\pi(t, H)= \begin{cases}\frac{1}{b} \mathrm{e}^{\left(\frac{x+t-m}{b}\right)} & \text { for } H_{t}=1 \\ \frac{1}{b} \mathrm{e}^{\left(\frac{x+t-m}{b}\right)}+k_{1}+k_{2} t & \text { for } H_{t}=2 \\ 0 & \text { for } H_{t}=3\end{cases}
$$

We calibrate the health shock using German cancer data. ${ }^{7}$ We weight the gender specific data equally and do not distinguish between genders in the simulation. This yields an overall lifetime risk of getting cancer of $46.75 \%$, a median age at diagnosis of 69 years and an absolute 5-year survival rate of $53.5 \%$. Furthermore, the data provides age and genderspecific cancer incidence rates for 5-year intervals up to an age of 85 . We calibrate the health shock rate $\kappa$ using a gender

\footnotetext{
${ }^{7}$ We use German data taken from "Cancer in Germany 2007/2008, German Centre for Cancer Registry Data \& Robert Koch Institute, 8th Edition 2012".
} 
averaged version of the age specific cancer incidence rates. We assume the following functional form for the health shock rate

$$
\kappa(t)=a \mathrm{e}^{-\left(\frac{\min (t, 65)-b}{c}\right)^{2}}
$$

with constant parameters $a, b, c$. Since we do not have data for ages higher than 85, for simplicity we assume that cancer rates are constant for agents older than 85 years. We obtain the parametrization $a=0.02489, b=66.96$ and $c=29.42$. Figure 1 illustrates the data points and our calibration of $\kappa$.

\section{[INSERT FIGURE 1 ABOUT HERE]}

For the calibration of the magnitude of the impact of the cancer shock on the mortality intensity $\left(k_{1}, k_{2}\right)$ we use the absolute average 5-year survival probability. Since there is an age dependency, we split the effect in a constant part $k_{1}$ and an age dependent part $k_{2}$. We calibrate $k_{1}$ and $k_{2}$ such that the simulated average 5-year survival probability and simulated death distribution match the empirical ones from the data. Here, we use German mortality data. ${ }^{8}$ For the shock impact, the calibration yields $k_{1}=0.048$ and $k_{2}=0.0008$. Considering the Gompertz mortality risk parameters, we set the age at $t=0$ to $x=20$, the $\mathrm{x}$-axis displacement to $m=89.45$ and the growth rate (steepness parameter) to $b=6.5$. Figure 2 compares our simulated yearly death rates with the empirical death rates in Germany.

\section{[INSERT FIGURE 2 ABOUT HERE]}

Our simulation fits the above-mentioned empirical means well: The average time of death is 80.5, the median age at diagnosis is 69 , and over the lifetime $45.8 \%$ of the population face a health shock. The absolute 5-year survival rate is 54.3\%. Figure 3 shows the histogram of health shocks and death shocks and the corresponding health-state distribution of the wage earner in our simulation.

\section{[INSERT FIGURE 3 ABOUT HERE]}

\footnotetext{
${ }^{8}$ The German mortality data is taken from "Sterbetafel 2009/11, Statistisches Bundesamt, 2013".
} 
Labor Income For the income dynamics (see equation (3.1)), we use the labor income calibration from Munk and Sørensen (2010), which is a continuous-time version of the Cocco, Gomes, and Maenhout (2005) results. They estimate the labor income process using PSID data dependening on the agent's education. Its drift term is modeled as

$$
\mu_{Y}(t)= \begin{cases}\xi_{0}+b+2 c t+3 d t^{2} & \text { for } t<T_{R} \\ -(1-P) & \text { for } T_{R} \leq t \leq T_{R}+1 \\ 0 & \text { for } t>T_{R}+1\end{cases}
$$

In the benchmark calibration, we assume that the wage earner has a high school education and set the corresponding parameters according to Munk and Sørensen (2010). We use a retirement age of $65\left(T_{R}=45\right)$, an age- and education-independent real wage increase of $\xi_{0}=0.02$ and an initial income of $Y_{0}=19107$. The drift polynomial is given by $b=0.1682, c=-0.00323, d=$ 0.000020 and the retirement income reduction parameter is $P=0.68212$. We also assume a different volatility parameter before and after retirement

$$
\sigma_{Y}(t)= \begin{cases}\sigma_{Y}^{w} & \text { for } t<T_{R} \\ \sigma_{Y}^{r} & \text { for } t \geq T_{R}\end{cases}
$$

where we use $\sigma_{Y}^{w}=0.2$ and $\sigma_{Y}^{r}=0$ in the benchmark calibration. In the same manner, we fix the correlation parameter

$$
\rho(t)=\left\{\begin{array}{ll}
\rho^{w} & \text { for } t<T_{R} \\
\rho^{r} & \text { for } t \geq T_{R}
\end{array} .\right.
$$

Following Munk and Sørensen (2010), we assume zero correlation $\left(\rho^{w}=0, \rho^{r}=0\right)$. If a jump occurs (critical illness or death), the income is reduced. In the critical illness case, we assume that the wage earner loses part of his income because he has to reduce his work effort. ${ }^{9} \mathrm{We}$ suppose that income decreases by $20 \%$, i.e. $p^{1,2}\left(t<T_{R}\right)=0.8$. If the critical illness occurs during retirement, the pension is however unaffected, i.e. $p^{1,2}\left(t \geq T_{R}\right)=1$. In both cases,

\footnotetext{
${ }^{9}$ In practice, an agent could buy disability insurance, but this usually does not cover all loses. At least potential future wage increases cannot be insured.
} 
the income volatility remains unchanged. In the benchmark calibration, we do not include a social security system which is studied as a robustness check (see Section 7). Hence, we set $p^{1,3}=p^{2,3}=0$ such that the family has no income if the wage earner dies. Figure 4 depicts the income profile of the wage earner and of the family over the life cycle.

\section{[INSERT FIGURE 4 ABOUT HERE]}

Long-term Life Insurance We assume a competitive insurance market, which leads to an actuarially fair insurance. First, we consider the continuation case where no intervention takes place. Then, the family only has to pay the insurance premium. The annual insurance premium $\iota(I)$ is assumed to be constant over time and is defined by the actuarial fairness criterion at $t=0$. Therefore, the expected discounted value of the insurance premia, $\Sigma_{\text {agent }}$, is equal to the the expected discounted value of the payments of the insurance company to the family, $\Sigma_{i n s}$, i.e.

$$
\Sigma_{\text {agent }}(0, I)=\Sigma_{\text {ins }}(0, I)
$$

with

$$
\begin{aligned}
\Sigma_{\text {agent }}(0, I) & =\mathrm{E}_{0}\left[\int_{0}^{T_{I}} \mathrm{e}^{-r s} \frac{\iota(I)}{1+\psi_{a d}+\psi_{t r}} \mathbb{1}_{\left\{s<\tau^{D}\right\}} d s\right] \\
& =\frac{\iota(I)}{1+\psi_{a d}+\psi_{t r}} \frac{1}{r}\left(1-\mathrm{E}_{0}\left[\mathrm{e}^{-r \min \left\{\tau^{D}, T_{I}\right\}}\right]\right),
\end{aligned}
$$

and

$$
\Sigma_{i n s}(0, I)=\mathrm{E}_{0}\left[\int_{0}^{T_{I}} \mathrm{e}^{-r s} I d \mathbb{1}_{\left\{s \geq \tau^{D}\right\}}\right]=\int_{0}^{T_{I}} \mathrm{e}^{-r s} I f_{D}(s) d s,
$$

where $f_{D}$ is the probability density function of $\tau^{D}$. The constant $\psi_{a d}$ captures annual administrative costs and the constant $\psi_{t r}$ captures deferred acquisition costs that are paid with the annual premium. Hence, the annual insurance premium can be expressed as

$$
\iota(I)=\frac{\operatorname{Ir}\left(1+\psi_{a d}+\psi_{t r}\right) \int_{0}^{T_{I}} f_{D}(s) \mathrm{e}^{-r s} d s}{1-\mathrm{E}_{0}\left[\mathrm{e}^{-r \min \left(\tau^{D}, T_{I}\right)}\right]} .
$$


Next, we consider the intervention case, i.e. a situation where the family increases or decreases the insurance sum $I$. If an intervention $\left(\zeta_{i}, \omega_{i}\right)$ takes place, the family must pay a lump-sum payment $\eta\left(\zeta_{i}, \omega_{i}, I_{\zeta_{i}}\right)$. This payment is necessary since the insurance premium $\iota$ is calculated based on survival patterns at $t=0$. Therefore, an insurance contract starting at $\zeta_{i}>0$ requires an adjusted premium. If the family reduces protection, $\omega_{i}<0$, no lump-sum payment is made. ${ }^{10}$ This relates to the comments on surrender values in Section 3. Reduction of the insurance corresponds to partial surrender and we assume that there is no (partial) surrender value. $^{11}$ Also, no access to the life settlement market is modelled. If the family increases insurance protection, $\omega_{i}>0$, we assume that the insurance company takes previously paid premia into account so that the lump-sum payment is

$$
\begin{array}{r}
\eta\left(\zeta_{i}, \omega_{i}, I_{\zeta_{i}}\right)=\left(1+\psi_{a d}+\psi_{t r}\right)\left(\Sigma_{i n s}\left(\zeta_{i}, I_{\zeta_{i}}\right)-\Sigma_{\text {agent }}\left(\zeta_{i}, I_{\zeta_{i}}\right)\right. \\
\left.-\Sigma_{i n s}\left(\zeta_{i}, I_{\zeta_{i}}-\omega_{i}\right)+\Sigma_{\text {agent }}\left(\zeta_{i}, I_{\zeta_{i}}-\omega_{i}\right)\right)
\end{array}
$$

where the two last terms depend on the previous insurance sum and capture the retrospective reserve. Note that they vanish in the special case where the family has no previous insurance protection. The variables $\Sigma_{i n s}\left(\zeta_{i}, I_{\zeta_{i}}\right)$ and $\Sigma_{\text {agent }}\left(\zeta_{i}, I_{\zeta_{i}}\right)$ denote the conditional present values of the payments to the family and to the insurance company:

$$
\begin{aligned}
\Sigma_{i n s}\left(\zeta_{i}, I_{\zeta_{i}}\right) & =\int_{\zeta_{i}}^{T_{I}} \mathrm{e}^{-r\left(s-\zeta_{i}\right)} I_{\zeta_{i}} f_{D}\left(s \mid \min \left(\tau^{D}, \tau^{H}\right)>\zeta_{i}\right) d s, \\
\Sigma_{\text {agent }}\left(\zeta_{i}, I_{\zeta_{i}}\right) & =\frac{\iota\left(I_{\zeta_{i}}\right)}{1+\psi_{a d}+\psi_{t r}} \frac{1}{r}\left(1-\mathrm{E}_{\zeta_{i}}\left[\mathrm{e}^{-r\left(\min \left(\tau^{D}, T_{I}\right)-\zeta_{i}\right)} \mid \min \left(\tau^{D}, \tau^{H}\right)>\zeta_{i}\right]\right),
\end{aligned}
$$

where we condition on the family being in the insurance market, i.e. being healthy and alive. The continuous premium $\iota$ is calculated according to (4.3). Notice that a valid intervention also requires $\zeta_{i} \leq T_{C}$.

To summarize, there are two cases: If no intervention takes place, the family must pay the insurance premium $\iota(I)$. If an intervention $\left(\zeta_{i}, \omega_{i}\right)$ takes place, an additional lump-sum payment

\footnotetext{
${ }^{10}$ Note that in countries like Germany a term life insurance has usually no repurchase value.

${ }^{11}$ Our results are robust to this assumption. In robustness checks not reported here, we have assumed that the surrender value is $90 \%$ of the present value of the contract. Our main results however hardly change.
} 
becomes due

$$
\eta\left(\zeta_{i}, \omega_{i}, I_{\zeta_{i}}\right)= \begin{cases}0 & \text { if } \omega_{i} \leq 0, \\ \left(1+\psi_{\text {ad }}+\psi_{\text {tr }}\right)\left(\Sigma_{\text {ins }}\left(\zeta_{i}, I_{\zeta_{i}}\right)-\Sigma_{\text {agent }}\left(\zeta_{i}, I_{\zeta_{i}}\right)\right. & \\ \left.-\Sigma_{\text {ins }}\left(\zeta_{i}, I_{\zeta_{i}}-\omega_{i}\right)+\Sigma_{\text {agent }}\left(\zeta_{i}, I_{\zeta_{i}}-\omega_{i}\right)\right) & \text { else. }\end{cases}
$$

We allow the family to choose among insurance contracts with payouts specified by $\mathcal{I}$ (see equation (3.2)). The family is able to change its insurance exposures until the wage earner is $70\left(T_{C}=50\right)$. The insurance contract expires at the age of $75\left(T_{I}=55\right)$. These ages are typical for German term life insurance contracts.

We set the administrative fee $\left(\psi_{a d}=2.99 \%\right)$ and the transaction fee $\left(\psi_{t r}=5.05 \%\right)$ to the average values of the German life insurance market. ${ }^{12}$ We discretize the conditional expectations $\mathrm{E}_{t}\left[\mathrm{e}^{-r \min \left(\tau^{D}, T_{I}\right)} \mid \min \left(\tau^{D}, \tau^{H}\right)>t\right]$ and $\int_{t}^{T_{I}} \mathrm{e}^{-r s} f_{D}\left(s \mid \min \left(\tau^{D}, \tau^{H}\right)>t\right) d s$, for $t \in$ $\left\{0,1, \ldots, T_{C}\right\}$ using German mortality data. ${ }^{13}$ For intermediate values of $t$ we use linear interpolation.

Preferences We choose standard values from the life cycle portfolio optimization literature for the risk aversion $(\gamma=4)$, the time preference rate $(\delta=0.03)$ and the bequest motive $(\varepsilon=1)$. In the benchmark calibration, the problem starts at time $t=0$, when the wage earner is 20 years old, and ends at $t=T=80$, when the wage earner is either 100 years old or dead. Following Love (2010), we calculate the consumption equivalence scaling parameter via

$$
\phi=\left(\alpha_{\text {Adult }}+0.7 \alpha_{\text {Child }}\right)^{0.7}
$$

where $\alpha_{\text {Adult }}$ is the number of adults and $\alpha_{C h i l d}$ is the number of children in the household. In the benchmark calibration, we study a family consisting of two adults and one child. Hence, we set the corresponding consumption scaling parameter to $\phi_{1,2}=2.0043$ if the wage earner is alive and to $\phi_{3}=1.4498$ if the wage earner is dead. We assume that the family starts with a financial wealth level that is twice the initial annual labor income of the wage earner, $X_{0}=2 Y_{0}$.

\footnotetext{
${ }^{12}$ Data about the transaction fees and administrative fees on the German insurance market are taken from "map-report no. 807-808".

${ }^{13}$ Mortality data is taken from Life table for Germany ("Sterbetafel 2009/11, Statistisches Bundesamt, 2013").
} 


\section{Benchmark Results}

This section provides our main results for the model introduced in Section 3 with the calibration presented in Section 4.

\subsection{Average Key Variables over the Life Cycle}

\section{[INSERT FIGURE 5 ABOUT HERE]}

Figure 5 depicts the average optimal decisions as well as the average financial wealth and income over the life cycle. Similar as in the above mentioned papers, financial wealth is humpshaped and the portfolio holdings are decreasing over the life cycle. The dark consumption line represents the consumption of the whole family. We see that consumption increases over the life cycle, although the slope decreases significantly after retirement. This is mainly due to two reasons. First, the labor income profile changes at retirement, especially the certainty of the retirement income leads to a flatter consumption path. Second, due to a higher mortality risk at older ages there are more families where the wage earner has already died. Then, the family has no more income and one person less to take care of, which both reduces consumption. The grey line represents the single person equivalent consumption. ${ }^{14}$ This line increases almost linearly over the life cycle, which indicates that on average the death of the wage earner does not lead to a reduced utility from consumption for the remaining family members. This may be either due to a high amount of accumulated financial wealth, or a term life insurance contract. As the insurance sum distribution graph shows, it is a combination of both for most families. About $65 \%$ of the families buy a long-term life insurance over the life cycle. At a young age, the families stay away from the insurance market, but start buying insurance at the age of about 30. Furthermore, the families increase the insurance sums over the life cycle and there is no age at which they systematically reduce the insurance exposures. Apparently, agents do not change the insurance contracts after the retirement age of 65 , although changes would be possible until

\footnotetext{
${ }^{14}$ This is a comparable one-person consumption level that is calculated by weighting the consumption of the family with the consumption equivalence scaling parameter $\frac{c_{t}}{\phi_{H_{t}}}$.
} 
the age of 70. This can be explained by the certainty of the retirement income. Consequently, there is no uncertainty with respect to human wealth. Hence, there is no reason to change the insurance decision. The increasing insurance sum over the life cycle might be counterintuitive at first. Since an older agent has on average more financial wealth and more income to hedge the effect of a health shock, one could expect the insurance demand to be lower compared to a situation with less income and wealth. However, there are opposing effects. First, for an older agent the contract duration is shorter. Hence, reducing an insurance exposure is relatively more costly than keeping it. Second, uncertainty with respect to human wealth and financial wealth significantly reduces for an older agent. Therefore, it is less likely that he faces a wealth and income state in which the contract is not affordable or too expensive relatively to his financial situation. These two effects dominate and yield an overall increasing insurance demand over the life cycle.

\subsection{Comparative Statics}

\section{[INSERT FIGURE 6 ABOUT HERE]}

To analyze the effects of age, income, financial wealth, and the previous insurance contract, we consider the policy functions. Figure 6 depicts the insurance demand for different levels of labor income. The lines represent different ages for a fixed level of financial wealth and a fixed previous insurance contract with insurance sum 100000 . For all ages, the insurance demand increases in the income level, which has two reasons: First, if income is large, then a higher insurance sum becomes affordable. Second, since an insurance is a hedge against the income loss upon death of the wager earner, a higher income increases this hedging motive. Furthermore, the figure highlights a time-dependence. The black line shows the policy function for a young wage earner at the age of 25. For a labor income of below 100000 , it is always optimal for the family to ignore any previous insurance contract and to surrender the contract. This leads to a loss of insurance protection and all previous paid premiums are lost as well. We document a large continuation interval ranging from about 175000 to 450000 , i.e. the family optimally sticks to the current insurance contract and no intervention takes place. The advantage is that 
the insurance protection maintains, past premiums are not lost and no expensive lump-sum costs must be paid for increasing the insurance sum. For a 50 year old middle-aged agent it is in general optimal to stick to the previous insurance decision, except for very high or low labor income. So the insurance choice at this age is also very robust. For an old retired agent at the age of 68 the optimal insurance sum crucially depends on the pension level. Furthermore, the insurance sum increases due to the certainty of the pension. This means that income volatility as a crucial source of uncertainty is no longer present. Overall, we document a strong dependence of the optimal insurance demand on labor income and time.

\section{[INSERT FIGURE 7 ABOUT HERE]}

Figure 7 depicts the corresponding policy functions dependent on financial wealth. Initially, we see that financial wealth has less impact on the insurance decision as income. However, this is not surprising, since the insurance is mainly used to hedge the loss of labor income in the case of death. Overall, the more financial wealth the agent has, the less insurance is optimal. This is intuitive, since there is less need for a fixed payout upon death if wealth is higher. For a middle-aged agent the continuation region includes all reasonable financial wealth levels. The young agent cancels the insurance if he has a huge amount of financial wealth (that is above the average wealth level at this age), whereas the old agent raises the insurance contract if his wealth is less than 1600000 . To summarize, the insurance decision is rather insensitive towards the level of financial wealth.

\section{[INSERT FIGURE 8 ABOUT HERE]}

Figure 8 shows how the policy functions depend on the previous insurance decision. It reveals the stickiness of this decision. The diagonal line depicts a situation where the agent keeps his insurance decision, i.e. the previous insurance contract equals the current optimal decision. Below the diagonal, the agent reduces insurance protection, whereas he increases protection above the diagonal. A young agent would cancel any contract, independent of its insurance sum, and thus stays away from the insurance market in the first place. In this case, the 
inflexibility of the contract is very severe, since the agent is tied to the contract for a potentially long time period or loses a significant amount of money if he cancels or reduces the contract prematurely. The uncertainty of human wealth at a young age amplifies this problem, as contracts are usually downward adjusted when human wealth has deteriorated and the current contract is not affordable any more. A middle-aged agent keeps a contract if the insurance sum is below 500000 . Contracts with higher insurance sums are reduced to this level. The old agent has a continuation region ranging from 200000 to 750 000, where he sticks to his contract. To summarize, the decisions at every age are pretty stable: Young agents stay away from the insurance market, whereas middle-aged agents usually keep their current positions.

\subsection{Impact of Critical Illness and Death Shocks}

\section{[INSERT FIGURE 9 ABOUT HERE]}

Figure 9 depicts the effects of a critical illness shock at the age of 50 (black lines) and a death shock at the age of 60 (grey lines) on the optimal behavior and the financial wealth and income evolution. If the wage earner dies, financial wealth jumps upwards since the family receives an insurance payment. Furthermore, it leads to a negative jump in family consumption due to the reduced number of family members, although there is only a minor change in the level of single person equivalent consumption. However, the family reduces the slope of its consumption path to adjust to the new income situation. Besides, the portfolio holdings are reduced to the classical Merton demands, since there is no labor income any more.

If the agent is first exposed to a critical illness shock, he becomes aware of a high probability of an early death. Consumption is reduced since labor income decreases and the family tries to accumulate financial wealth for the remaining family members. Portfolio holdings are reduced as well. Unfortunately, the agent cannot increase his insurance protection any more. Therefore, at the time of death the average insurance sum is less than $50 \%$ of the sum of an agent without previous health shock. Finally, the single person equivalent consumption is adjusted when the health shock occurs, and thus there is no significant decrease at the time of death. 
[INSERT FIGURE 10 ABOUT HERE]

Figure 10 illustrates a situation where the wage earner dies at the age of 30 . In the first setting there is no previous health shock (grey lines), whereas in the second setting there is a health shock at the age of 25 (dark lines). In this case, the family has only little time to accumulate financial wealth. Furthermore, most families do not buy any insurance at this age, which explains the very low average insurance sum. These two facts together with the early death of the wage earner reduces consumption of the family and also the single person equivalent consumption significantly. Buying a term life insurance contract could easily double the available financial wealth.

\section{Extending the Insurance Market}

In this section, we add additional insurance products to the model and discuss their effects on the long-term life insurance demand. More precisely, we give the agent the opportunity to buy annuities, short-term life insurances and a health insurance.

\subsection{Short-term Life Insurance}

Fist, we add a short-term life insurance as in Richard (1975) that provides coverage for a short time interval. If the wage earner is alive and healthy $\left(H_{t}=1\right)$ and in the insurance market $\left(t \leq T_{C}\right)$, the family can buy short-term life insurance products. It chooses the notional of the short-term contract $I^{\text {short }}>0$ and gets coverage for the next short time period of length $d t$. The family pays a premium at the rate

$$
\iota_{t}^{\text {short }}\left(I^{\text {short }}\right)=I^{\text {short }} \pi(t, 1)\left(1+\psi_{a d}+\psi_{t r}\right) .
$$

The premium is calculated such that the contract is actuarially fair and additionally involves fees. After that period, the agent can buy a new short-term life insurance that covers the next short time interval. 
[INSERT FIGURE 11 ABOUT HERE]

Figure 11 depicts the average demand for short-term or long-term life insurance contracts over the life cycle. Apart from the additional demand for short-term insurance, the results are similar to the benchmark case. Financial wealth, consumption and portfolio holdings are largely unaffected by giving the family access to short-term insurance. Besides, our findings indicate that there is no significant change in the demand for long-term insurance although the family buys short-term contracts over the life cycle. While the short-term contract is much cheaper and more flexible than the long-term contract for young families, it cannot be contracted in the state of critical illness $\left(H_{t}=2\right)$. Therefore, the short-term contract cannot provide any benefits after a health shock. Hence, the only possibility for the family to be insured in the state of critical illness is to contract long-term life insurance before a health shock occurs.

[INSERT FIGURE 12 ABOUT HERE]

Figure 12 depicts the average total demand for short-term and long-term life insurance contracts over the life cycle. Apparently, the total demand is hump-shaped with a peak at the age of 45 . This pattern is qualitatively in line with the empirical findings of Hong and Ríos-Rull (2012). These authors document lower participation rates for younger and older age groups than for middle aged agents. Quantitatively, however, our model suggests optimal insurance demands that are higher than the ones found in the data.

\subsection{Annuity Contract}

Now, we extend the model such that, additionally to the term life insurance, the family can buy annuities as long as the wage earner is alive. If the family contracts an annuity at some point $\zeta_{i}$, the insurance company pays out an annuity $A$ until the wage earner dies. The annuity is constant as long as the family does not change its annuity decision. The insurance company offers a set of annuity contracts with the following annual payments

$$
\mathcal{A}=\{0,6000,12000,18000,24000,30000\} .
$$


If the family changes its annuity decision, it pays a lump sum premium $\eta_{A}\left(\zeta_{i}, \omega_{i}, A_{\zeta_{i}}\right)$ to the insurance company. This payment takes the previous annuity decision, the new annuity decision and the age of the agent into account. It ensures an actuarially fair new contract, but it also involves a fee. The annuity choice adds an additional layer of complexity to the impulse control problem of the family. At an intervention time $\zeta_{i}$, the intervention action $\omega_{i}=\left(\omega^{I}, \omega^{A}\right)$ is split into an insurance action $\omega^{I}$ and an annuity action $\omega^{A}$. We require the intervention action to be chosen such that the new insurance sum and the new annuity is in the set of feasible contracts. To characterize the family's annuity decision recall that the annuity $A$ is constant as long as the family does not intervene. In the intervention case where the family increases the annuity, $\omega^{A}>0$, we assume that the insurance company takes previously paid lump sum payments into account. Therefore, the fair up-front payment for an intervention $\left(\zeta_{i}, \omega_{i}^{A}\right)$ is given by

$$
\eta_{A}\left(\zeta_{i}, \omega_{i}^{A}, A_{\zeta_{i}}\right)=\left(1+\psi_{a d}+\psi_{t r}\right)\left[\Sigma_{i n s}^{A}\left(\zeta_{i}, A_{\zeta_{i}}\right)-\Sigma_{i n s}^{A}\left(\zeta_{i}, A_{\zeta_{i}}-\omega_{i}^{A}\right)\right]
$$

Here the variables $\Sigma_{i n s}^{A}\left(\zeta_{i}, A_{\zeta_{i}}\right)$ denote the conditional present values of the annuities that are paid by the insurance company to the family:

$$
\Sigma_{i n s}^{A}\left(\zeta_{i}, A_{\zeta_{i}}\right)=\mathrm{E}_{\zeta_{i}}\left[\int_{\zeta_{i}}^{\tau^{D}} A_{\zeta_{i}} \mathrm{e}^{-r\left(s-\zeta_{i}\right)} \mathrm{d} s\right]
$$

where we condition on the agent being alive at $\zeta_{i}$. In our implementation, the conditional expectations are calculated as described in Section 4.

\section{[INSERT FIGURE 13 ABOUT HERE]}

Figure 13 depicts the average demand for annuities and long-term life insurance contracts over the life cycle. The insurance demand is slightly higher than in the benchmark case. Since families can buy annuities, there is a tendency that they turn some of their cash into additional income. This leads to a higher demand for life insurance contracts. Financial wealth, consumption and stock holdings are largely unaffected by adding annuities. Notice that the demand for annuities is in general relatively low. Agents buy annuities only in the last third of their lifetimes. Until an age of 55, the family does not contract an annuity (based on 100 
000 simulations). One reason for this finding is that the family already has a decent income. Since the income stream continues after retirement, the retirement income is similar to an annuity. Therefore, the annuity demand reflects how the family should supplement its income. This intuition conforms with the result that only families with a large financial wealth, but relatively poor income buy annuities.

\subsection{Health Expenses and Health Insurance}

Finally, we analyze the impact of exogenous out-of-pocket health expenses on the optimal insurance decision. ${ }^{15}$ Following Koijen, Van Nieuwerburgh, and Yogo (2013), we assume that the family has basic health insurance that covers the bulk of health expenditures. More precisely, we assume that the wage earner has employee health insurance in the active phase and Medicare in retirement. However the family faces additional out-of-pocket health expenses that are not covered by basic health insurance. As health shocks significantly increase the out-of-pocket health expenses, the family can contract a supplementary private health insurance as long as the wage earner is alive and healthy $\left(H_{t}=1\right)$. The health insurance decision can be made continuously and is denoted by

$$
\chi_{t}^{\text {health }}= \begin{cases}1 & \text { if the agent is insured at } t \\ 0 & \text { else. }\end{cases}
$$

If insured, $\chi_{t}^{\text {health }}=1$, the family pays an insurance premium $\iota_{t}^{\text {health }}$. In this case, the health insurance covers the additional expenses of the family when the wage earner suffers a health shock. The net income process $Y^{n e t}$ (net of health expenses and health insurance premia) is given by

$$
\left.Y_{t}^{\text {net }}=Y_{t}\left[1-\epsilon\left(t, H_{t}, \chi_{t}^{\text {health }}\right)\right]-\mathbb{1}_{\left\{\chi_{t}^{\text {health }}=1\right\}}\right\}_{t}^{\text {health }}
$$

\footnotetext{
${ }^{15}$ Some authors such as Yogo (2009) and Hugonnier, Pelgrin, and St-Amour (2013) allow for an endogenous choice of health expenses. In their settings, the agent can improve his health status by spending money on health investments. We abstract from endogenous health investments and assume exogenous health expenses as in Koijen, Van Nieuwerburgh, and Yogo (2013) or Ameriks, Caplin, Laufer, and Van Nieuwerburgh (2011).
} 
where $\epsilon\left(t, H_{t}, \chi_{t}^{\text {health }}\right)$ denotes the fraction of income that the family spends for health expenditures, net of health insurance premium and benefit payments. ${ }^{16}$ If a health shock occurs while the wage earner is insured, the insurance covers all additional out-of-pocked expenses, i.e.

$$
Y_{t} \epsilon(t, 2,0)-Y_{t} \epsilon(t, 1,0)
$$

This is the benefit paid by the health insurance company for the remaining life time of the wage earner after the health shock.

We calibrate the out-of-pocket health expenses such that they match the average US health expenses. The data comes from the Agency of Healthcare Research and Quality. ${ }^{17}$ It gives information about the average medical expenses for five age groups since 1996 and the respective out-of-pocket expenses. Furthermore, it provides expenses resulting from selected medical conditions, especially cancer. We estimate an average real increase in historical health expenses of about $2.9 \%$ per annum. For uninsured people, we parametrize $\left(R^{2}>0.99\right)$ out-of-pocket health expenses by

$$
E(t, H)= \begin{cases}1.81(t+x)^{2}-71.21(t+x)+1236 & \text { for } H=1, \\ 6.365(t+x)^{2}-149.9(t+x)+8460 & \text { for } H=2,\end{cases}
$$

where $x=20$ is the age of the wage earner at $t=0$. In order to convert the average health expenses into income fractions, we set $\epsilon\left(t, H_{t}, 0\right)=\frac{E\left(t, H_{t}\right)}{\overline{Y_{t}}}$ where $\overline{Y_{t}}$ denotes the expected income at time $t$.

For the calibration of the health insurance, we simulate 100000 paths given that the family is insured. We simulate the expected discounted payments $\Sigma_{i n s}^{H}(t)$ of the insurance company to the family at time $t$ :

$$
\Sigma_{\text {ins }}^{H}(t)=\frac{1}{\left|\left\{\omega \mid H_{t^{-}}^{\omega}=1\right\}\right|} \sum_{\omega \in\left\{\omega \mid H_{t^{-}}^{\omega}=1, H_{t}^{\omega} \neq 1\right\}} \int_{t}^{\tau^{\omega}} \mathrm{e}^{-r(s-t)} Y_{s}^{\omega}(\epsilon(s, 2,0)-\epsilon(s, 1,0)) d s,
$$

\footnotetext{
${ }^{16}$ De Nardi, French, and Jones (2010) show that out-of-pocket expenses are sharply increasing in both age and income.

${ }^{17}$ See http://meps.ahrq.gov/mepsweb/data_stats/quick_tables.jsp.
} 
where $\omega$ denotes a particular path. The corresponding insurance income $\Sigma_{\text {agent }}^{H}(t)$ is given by

$$
\Sigma_{\text {agent }}^{H}(t)=\frac{1}{\left|\left\{\omega \mid H_{t^{-}}^{\omega}=1\right\}\right|} \sum_{\omega \in\left\{\omega \mid H_{t}^{\omega}=1\right\}} \iota_{t}^{\text {health }} .
$$

Now, we calibrate the insurance premium such that for all ages the average income and expenses are identical. Finally, we add an administrative fee and a transaction fee to the actuarially fair premium. It turns out that the results of our calibration can be very well represented by the following exponential form

$$
\iota_{t}^{\text {health }}=\left(1+\psi_{a d}+\psi_{t r}\right)\left[2306 \mathrm{e}^{-\left(\frac{t-60.08}{16.48}\right)^{2}}+1677 \mathrm{e}^{-\left(\frac{t-48.13}{21.06}\right)^{2}}\right] .
$$

[INSERT FIGURE 14 ABOUT HERE]

Figure 14 depicts our results with exogenous health expenses. It turns out that the family has a strong demand for the private health insurance. Almost all young families contract the health insurance until an age of 45. When age increases, the premia increases rapidly and the family leaves the insurance market in $80 \%$ of the cases. Again optimal consumption and portfolio holdings are largely unaffected. Our results show that with exogenous health expenses, the demand for life insurance contracts decreases slightly. This decrease can be explained by the characteristics of the net income process. Including out-of-pocket health expenses lowers (net) human wealth. This reduces the hedging demand for mortality risk and in turn the demand for life insurance contracts.

\section{Robustness Checks}

This section presents robustness checks for our benchmark model. These checks involve different labor income volatilities, a calibration without health shock and a different bequest motive. We also discuss the main drivers that prevent families from increasing their long-term insurance demands. Furthermore, we give results for a calibration with a social security system that pays a widow's pension after the death of the wage earner. Additional robustness checks can be found in the appendix. 


\subsection{Labor Income Volatility}

\section{[INSERT FIGURE 15 ABOUT HERE]}

A term insurance allows a family to (partially) hedge the risk resulting from an early death of the wage owner. Since the death of the wage earner predominately leads to a loss of labor income, the optimal insurance choice crucially depends on the labor income process. A negative feature of a long-term insurance contract is the stickiness of its premia. Consequently, such an insurance contract amplifies the effect of negative labor income shock. For instance, if a family is optimally insured and a negative labor income shock occurs, then the family has too much insurance protection given the actual income situation and must cut down on consumption. Alternatively, the family can reduce or terminate the insurance contract yielding to a loss, since term life insurance has no surrender value. In both cases, the effect of a negative labor income shock is stronger if the family has a higher insurance exposure. Therefore, hedging mortality risk comes at the cost of amplifying the effect of a negative labor income shock. In line with these findings, Figure 15 shows that the insurance demand is significantly higher for families with lower income volatility. Besides, these families also buy insurance earlier so that young families are insured as well.

\subsection{Health Shocks}

[INSERT FIGURE 16 ABOUT HERE]

A health shock prevents the family from increasing the insurance protection or buying a new contract. Intuitively, one might expect that the family anticipates this restriction and buys more protection at a young age. Figure 16 compares the benchmark model with an alternative

calibration without health shocks. Surprisingly, our findings document a higher insurance demand in the case without health shocks. The reason is that a health shock can be interpreted as a warning that death becomes more likely. If the wage earner faces a health shock, the family knows that he will die with a high probability in the next few years. Although an early death is clearly negative for the family, the health shock partially resolves uncertainty about the 
timing of dying, which itself is beneficial. With this new information the family is better able to plan consumption and investment decisions. Therefore, the family reduces consumption in order to accumulate more wealth, which can be seen in Figure 9 and 10. Due to the additional savings, the insurance demand goes down. Notice that in our benchmark calibration labor income is reduced after a health shock, which triggers a decrease in consumption. This is however also true in a calibration where the labor income is not reduced in the critical illness state. Furthermore, one might argue that the increased insurance demand without health shock results from the fact that in this setup there is no state in which the insurance acquisition is forbidden. However, the results also hold when we only consider families that do not face a health shock.

\subsection{Bequest Motive}

\section{[INSERT FIGURE 17 ABOUT HERE]}

There is empirical evidence that bequest can be interpreted as a luxury good. In this case, households are less risk averse concerning bequest than intermediate consumption. Following De Nardi, French, and Jones (2010) and Lockwood (2012), we now study a version of our model with a more general bequest motive given by

$$
u\left(X_{T}\right)=\varepsilon \frac{1}{1-\gamma}\left(k+X_{T}\right)^{1-\gamma} .
$$

Notice that $k$ and $\gamma$ jointly determine the curvature of the bequest function. For $k=0$ we obtain standard CRRA utility from bequest, which implies that households are equally risk averse concerning bequest and consumption. For $k>0$, the marginal utility of consumption declines faster than the marginal utility of bequest implying a higher risk aversion for bequest. We recalibrate the preference parameters according to De Nardi, French, and Jones (2010). We choose $k=273000$ and a bequest weight of $\varepsilon=2.36$. Figure 17 shows that the choice of the bequest motive has a small impact on the insurance decision and the portfolio holdings. However, there is a significant reduction in consumption leading to a consumption hump around the retirement date. 


\subsection{Social Security System}

\section{[INSERT FIGURE 18 ABOUT HERE]}

In this paragraph, we add a social security system to the model that pays the family an income after the death of the wage earner. This can be interpreted as a widow's pension and the corresponding income stream is calibrated using data of the German social security system. Therefore, we recalibrate the effects of the wage earner's death on the income process as follows: ${ }^{18}$

$$
p^{1,3}(t)=p^{2,3}(t)= \begin{cases}0.55 \cdot 0.68212(1-0.108) & \text { for } t<40, \\ 0.55 \cdot 0.68212(1-(43-t) 0.036) & \text { for } 40 \leq t<43, \\ 0.55 \cdot 0.68212 & \text { for } 43 \leq t<45 \\ 0.55 & \text { for } t \geq 45 .\end{cases}
$$

Notice that a widow receives at most about $55 \%$ of the pension. Besides, before retirement $(t<45)$ there is also an adjustment for the replacement rate of 0.68212 and deductions. The income jump $p^{1,2}$ if the wage earner gets unhealthy remains unchanged.

Figure 18 depicts the average key variables over the life cycle. Compared to an economy without social security system (see Figure 5), the average income is higher and does not approach zero. Furthermore, the optimal consumption now shows a hump-shaped pattern. The financial wealth and the portfolio holdings are only little affected. The insurance sum distribution highlights that about $90 \%$ of the population buy term life insurance over the lifetime, which is a significant increase. However, one of our main results stands: Young families do not participate in term life insurance markets. Figure 19 compares the average insurance demand to the benchmark results without social security system. One might conjecture that a social security system crowds out most of the insurance demand and, consequently, the insurance demand is significantly reduced. Our results however point in a different direction: With a social security system, the insurance demand significantly increases for all ages. This increase can be explained by the changes in the

\footnotetext{
${ }^{18}$ Details can be found in the German Social Security Code (SGB).
} 
characteristics of the income process. First, the human wealth is higher due to the additional payment. Second, uncertainty of human wealth reduces since the income loss at death is less pronounced and the widow's pension is deterministic.

\section{[INSERT FIGURE 19 ABOUT HERE]}

\section{Conclusion}

This paper studies the optimal insurance demand of a family that is exposed to health shock and mortality risk. The wage earner receives an unspanned income stream and can buy term life insurance up to the age of 70 as long as he is healthy. We model the available longterm insurance contracts in a realistic way by assuming that decisions can only be revised at certain costs. The combination of unspanned income as well as the stickiness of the insurance contracts reduces the long-term insurance demand significantly. In particular, it is optimal for young families to stay away from this insurance market. These results are robust to adding short-term insurance, annuities and health insurance. For instance, if families have also access to short-term insurance, they buy these contracts at a young age without demanding long-term insurance. This decision leaves the possibility open that a health shock prevents them from renewing short-term contracts. In this case, the family might suffer financial hardship when the wage earner eventually dies. 


\section{References}

Ameriks, John, Andrew Caplin, Steven Laufer, and Stijn Van Nieuwerburgh, 2011, The Joy of Giving or Assisted Living? Using Strategic Surveys to Separate Public Care Aversion from Bequest Motives, Journal of Finance 66, 519-561.

Bruhn, Kenneth, and Mogens Steffensen, 2011, Household consumption, investment and life insurance, Insurance: Mathematics and Economics 48, 315-325.

Campbell, Ritchie A., 1980, The Demand for Life Insurance: An Application of the Economics of Uncertainty, The Journal of Finance 35, 1155-1172.

Cocco, João F., and Francisco J. Gomes, 2012, Longevity risk, retirement savings, and financial innovation, Journal of Financial Economics 103, 507-529.

Cocco, João F., Francisco J. Gomes, and Pascal J. Maenhout, 2005, Consumption and Portfolio Choice over the Life Cycle, Review of Financial Studies 18, 491-533.

De Nardi, Mariacristina, Eric French, and John Jones, 2010, Why Do the Elderly Save? The Role of Medical Expenses, Journal of Political Economy 118, 39-75.

Fang, Hanming, and Edward Kung, 2012, Why Do Life Insurance Policyholders Lapse? The Roles of Income, Health and Bequest Motive Shock, Working Paper, NBER.

Fier, Stephen G., and Andre P. Liebenberg, 2013, Life Insurance Lapse Behavior, North American Actuarial Journal 17, 153-167.

Gottlieb, Daniel, and Kent Smetters, 2012, Narrow Framing and Life Insurance, Working Paper, NBER.

Gottlieb, Daniel, and Kent Smetters, 2014, Lapse-Based Insurance, Working Paper.

Hong, Jay H., and José-Víctor Ríos-Rull, 2012, Life Insurance and Household Consumption, American Economic Review 102, 3701-30. 
Huang, Huaxiong, Moshe A. Milevsky, and Thomas S. Salisbury, 2012, Optimal retirement consumption with a stochastic force of mortality, Insurance: Mathematics and Economics 51, 282-291.

Huang, Huaxiong, Moshe A. Milevsky, and Jin Wang, 2008, Portfolio Choice and Life Insurance: The CRRA Case, Journal of Risk and Insurance 75, 847-872.

Hubener, Andreas, Raimond Maurer, and Ralph Rogalla, 2014, Optimal Portfolio Choice with Annuities and Life Insurance for Retired Couples, Review of Finance 18, 147-188.

Hugonnier, Julien, Florian Pelgrin, and Pascal St-Amour, 2013, Health and (other) Asset Holdings, Review of Economic Studies 80(2), 663-710.

Koijen, Ralph S.J., Stijn Van Nieuwerburgh, and Motohiro Yogo, 2013, Health and Mortality Delta: Assessing the Welfare Cost of Household Insurance Choice, Working Paper, NBER.

Kraft, H., and M. Steffensen, 2008, Optimal Consumption and Insurance: A Continuous-Time Markov Chain Approach, ASTIN Bulletin 28, 231-257.

Lockwood, Lee M., 2012, Bequest motives and the annuity puzzle, Review of Economic Dynamics 15, 226-243.

Love, David A., 2010, The Effects of Marital Status and Children on Savings and Portfolio Choice, Review of Financial Studies 23, 385-432.

Merton, Robert C., 1969, Lifetime Portfolio Selection under Uncertainty: The Continuous-Time Case, Review of Economics and Statistics 51, 247-257.

Merton, Robert C., 1971, Optimum Consumption and Portfolio Rules in a Continuous-Time Model, Journal of Economic Theory 3, 373-413.

Merton, Robert C., 1975, Theory of Finance from the Perspective of Continuous Time, The Journal of Financial and Quantitative Analysis 10, 659-674. 
Munk, Claus, and Carsten Sørensen, 2010, Dynamic asset allocation with stochastic income and interest rates, Journal of Financial Economics 96, 433-462.

Pliska, Stanley R., and Jinchun Ye, 2007, Optimal life insurance purchase and consumption/investment under uncertain lifetime, Journal of Banking \& Finance 31, 1307-1319.

Richard, Scott F., 1975, Optimal consumption, portfolio and life insurance rules for an uncertain lived individual in a continuous time model, Journal of Financial Economics 2, 187-203.

Yaari, Menahem E., 1965, Uncertain Lifetime, Life Insurance, and the Theory of the Consumer, Review of Economic Studies 32, 137-150.

Yogo, Motohiro, 2009, Portfolio Choice in Retirement: Health Risk and the Demand for Annuities, Housing, and Risky Assets, Working Paper, NBER.

\section{A Additional Robustness Checks}

\section{A.1 Insurance Structure}

[INSERT FIGURE 20 ABOUT HERE]

The structure of a term life insurance contract varies among insurance companies. Especially the fees $\psi_{t r}, \psi_{a d}$, the date $T_{C}$ until the insurance decision can be revised and the expiration date $T_{I}$ can be different. Figure 20 depicts the effect of a change of the fees. We compare the average fees of the benchmark result (grey line) to a regime with high fees (light line) and without fees (dark line). Clearly, the insurance demand decreases if fees are raised. However, although the fees are increased significantly, the decrease in insurance demand is not dramatic. This indicates that the insurance profit, captured by the fees, has a rather small effect on the insurance demand. 


\section{A.2 Family Size}

[INSERT FIGURE 21 ABOUT HERE]

Figure 21 confirms the intuition that a larger family buys more insurance protection. In our model, this is captured by the consumption scaling parameter $\phi_{H}$. The relative difference in the consumption scaling parameter in state $H=1,2$ and $H=3$ is smaller, the larger the family. Consequently, for a large family more consumption is needed to obtain the same single-person equivalent utility level. If the wage earner dies, the whole income is lost, but the bigger part of consumption remains if the family size is large. This increases the insurance demand.

\section{A.3 Risk Aversion}

[INSERT FIGURE 22 ABOUT HERE]

Figure 22 shows the impact of the relative risk aversion on the average insurance sum. Apparently, risk aversion has little impact before the age of 30 and after retirement. In between, more risk averse agents demand less insurance. Hence, a more risk averse agent perceives the insurance contract as more risky compared to financial investments (stocks, bonds). However, overall the degree of relative risk aversion has only little impact on the insurance decision. 


\section{Financial Market}

\begin{tabular}{|c|c|c|}
\hline$\mu_{S}$ & Stock drift & 0.06 \\
\hline$\sigma_{S}$ & Stock volatility & 0.2 \\
\hline$r$ & Bond drift & 0.02 \\
\hline \multicolumn{3}{|c|}{ Preferences } \\
\hline$\delta$ & Time preference rate & 0.03 \\
\hline$\gamma$ & Relative risk aversion & 4 \\
\hline$\varepsilon$ & Weight of the bequest motive & 1 \\
\hline$\alpha_{\text {Adult }}$ & Number of adults in the household & 2 \\
\hline$\alpha_{C h i l d}$ & Number of children in the household & 1 \\
\hline$T$ & Time horizon of the family & 80 \\
\hline$X_{0}$ & Initial financial wealth & 38214 \\
\hline \multicolumn{3}{|c|}{ Mortality Risk } \\
\hline$x$ & Age of the wage earner at $t=0$ & 20 \\
\hline$m$ & $\mathrm{X}$-axis displacement & 89.45 \\
\hline$b$ & Steepness parameter & 6.5 \\
\hline$k_{1}$ & Constant impact of a health shock & 0.048 \\
\hline$k_{2}$ & Age-dependent impact of a health shock & 0.0008 \\
\hline \multicolumn{3}{|c|}{ Health Shock Risk } \\
\hline$a$ & Scaling parameter & 0.02489 \\
\hline$b$ & $\mathrm{X}$-axis displacement & 66.96 \\
\hline$c$ & Steepness parameter & 29.42 \\
\hline \multicolumn{3}{|c|}{ Income } \\
\hline$\xi_{0}$ & Age and education independent wage increase & 0.02 \\
\hline$b$ & Education dependent wage increase & 0.1682 \\
\hline$c$ & Education and age dependent wage increase parameter & -0.00323 \\
\hline$d$ & Education and age dependent wage increase parameter & 0.00002 \\
\hline$P$ & Replacement ratio & 0.68212 \\
\hline$T_{R}$ & Retirement time & 45 \\
\hline$Y_{0}$ & Initial income & 19107 \\
\hline$\sigma_{Y}^{w}$ & Volatility while working & 0.2 \\
\hline$\sigma_{Y}^{r}$ & Volatility during retirement & 0 \\
\hline$\rho^{w}$ & Correlation with the stock while working & 0 \\
\hline$\rho^{r}$ & Correlation with the stock during retirement & 0 \\
\hline$p^{1,2}\left(t<T_{R}\right)$ & Income level after a health shock while working & 0.8 \\
\hline$p^{1,2}\left(t \geq T_{R}\right)$ & Income level after a health shock during retirement & 1 \\
\hline$p^{1,3}$ & Income level at death without previous health shock & 0 \\
\hline$p^{2,3}$ & Income level at death with previous health shock & 0 \\
\hline \multicolumn{3}{|c|}{ Insurance } \\
\hline$\psi_{a d}$ & Administrative fee & 0.0299 \\
\hline$\psi_{t r}$ & Transaction fee & 0.0505 \\
\hline$T_{C}$ & Latest time for changing the insurance contract & 50 \\
\hline$T_{I}$ & Contract maturity & 55 \\
\hline
\end{tabular}

Table 1: Benchmark Calibration Parameters. 


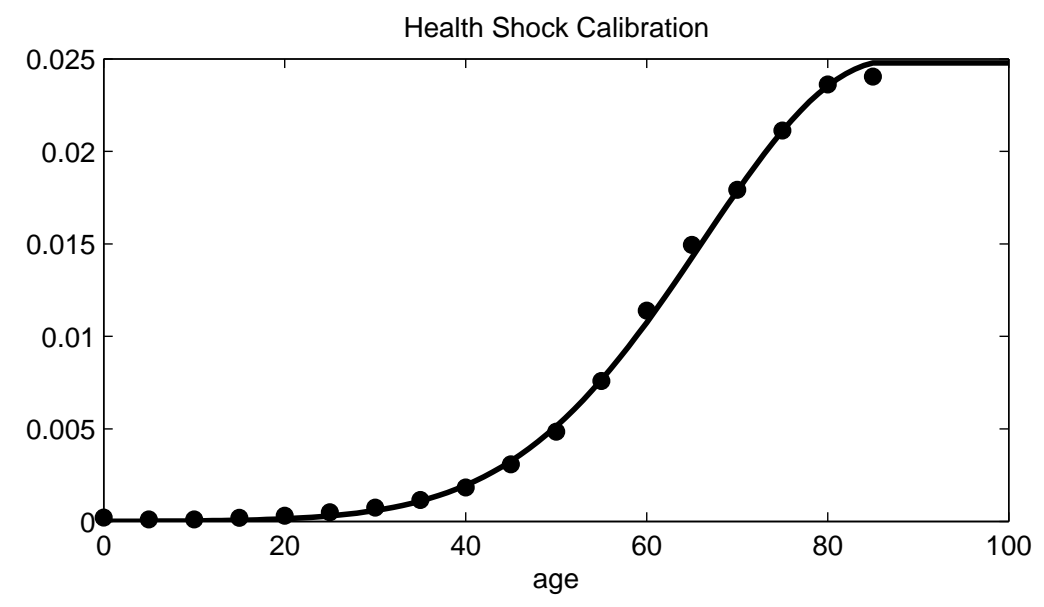

Figure 1: Health Shock Calibration. The figure shows empirical gender averaged 5-year cancer detection rates and our fitted curve $\kappa$. The empirical realizations (points) are gender averaged values from "Cancer in Germany 2007/2008, German Centre for Cancer Registry Data \& Robert Koch Institute, 8th Edition 2012". The parameters for our fitted curve $\kappa$ (solid line) are given in Section 4.

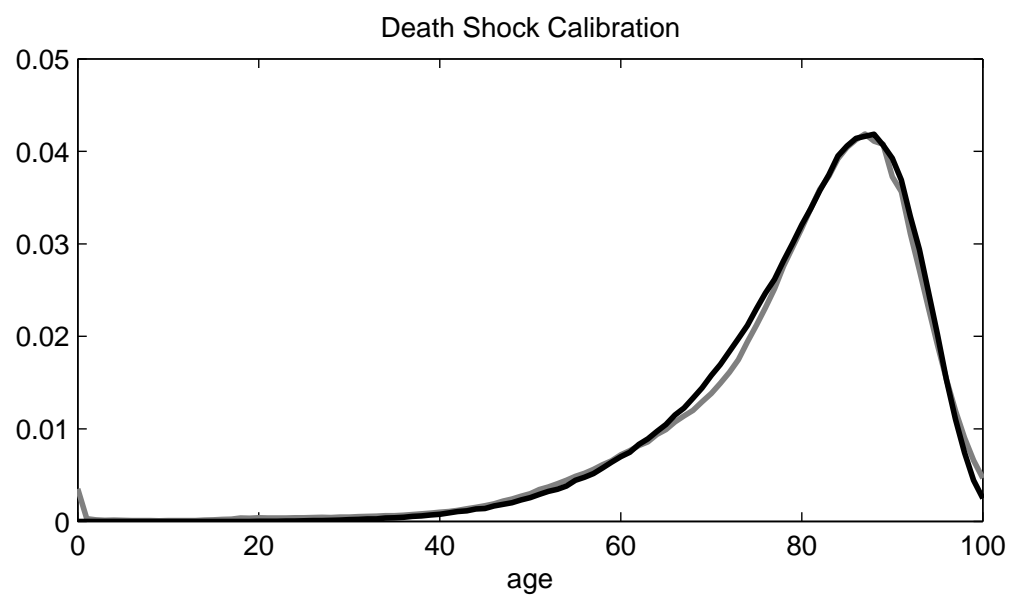

Figure 2: Death Shock Calibration. The figure depicts the number of yearly deaths for a normalized population of size 1. The mortality data (grey line) is gender averaged from a life table for Germany ("Sterbetafel 2009/11, Statistisches Bundesamt, 2013"). Our simulated values (dark line) are the averages from 100000 death shock simulations using the biometric risk calibration of Section 4 
a) Health Shock Distribution

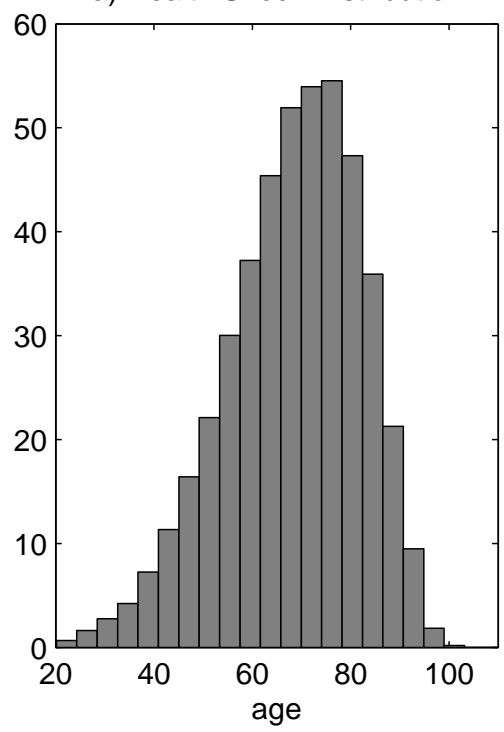

b) Death Shock Distribution

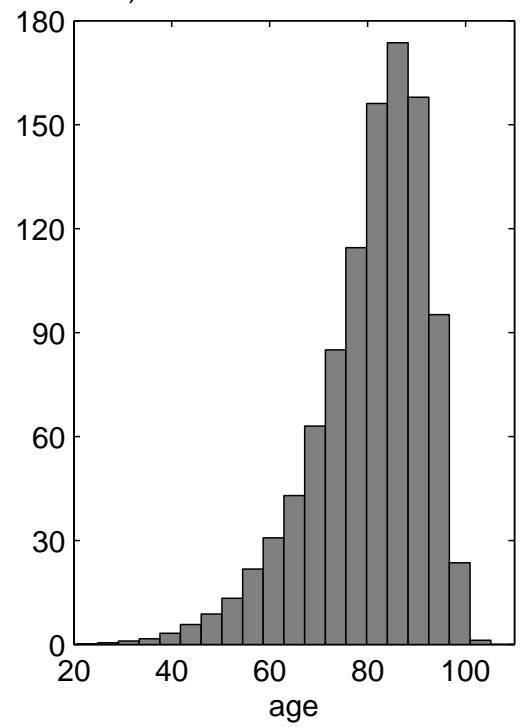

c) State Distribution

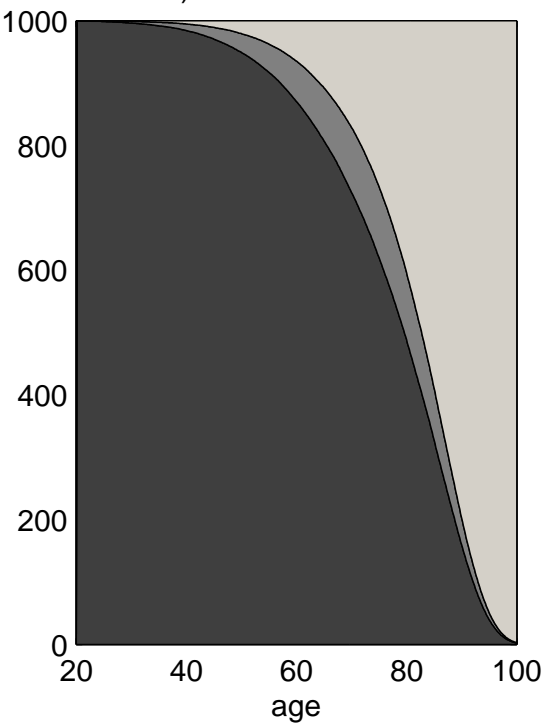

Figure 3: Simulated Biometric Risk Distribution. The graphs show the results of 100000 simulated life cycles with the biometric risk parametrization of Section 4. a) depicts the histogram of the health shocks in our simulation. b) shows the corresponding histogram of death shocks. c) shows the state distribution of the families. The dark area corresponds to families with a healthy wage earner $(A=1)$, the middle grey area represents unhealthy agents $(A=2)$ and the light area marks families with a dead wage earner $(A=3)$.

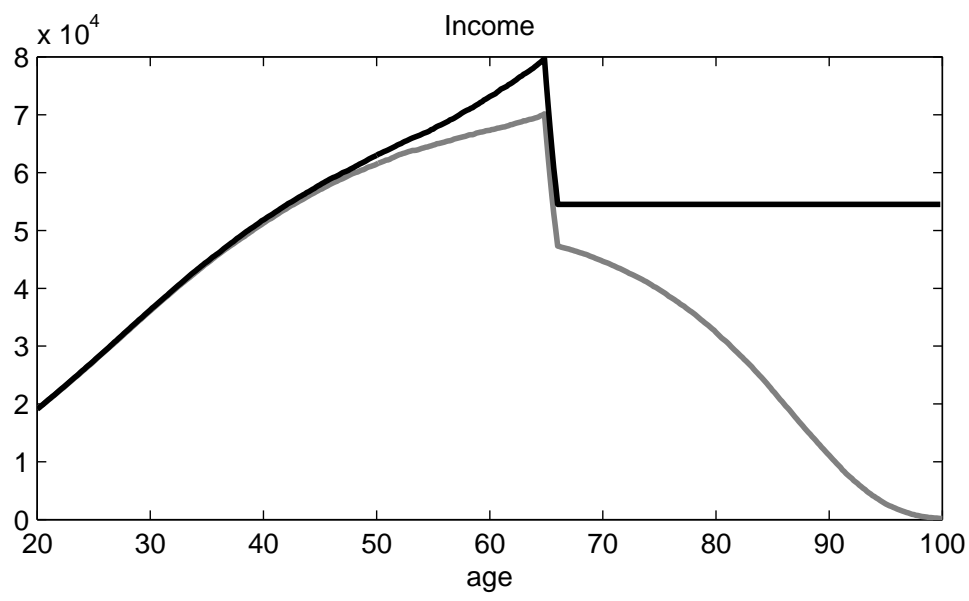

Figure 4: Expected Income Profile over the Life Cycle. The figure depicts the expected income of a wage earner conditional on survival (dark line) assuming that he has a high school education. The grey line gives the expected income of the family and incorporates the biometric risk of the wage earner. The labor income and biometric risk parameter values are stated in Section 4 and the lines depict the average values of 100000 simulations. 

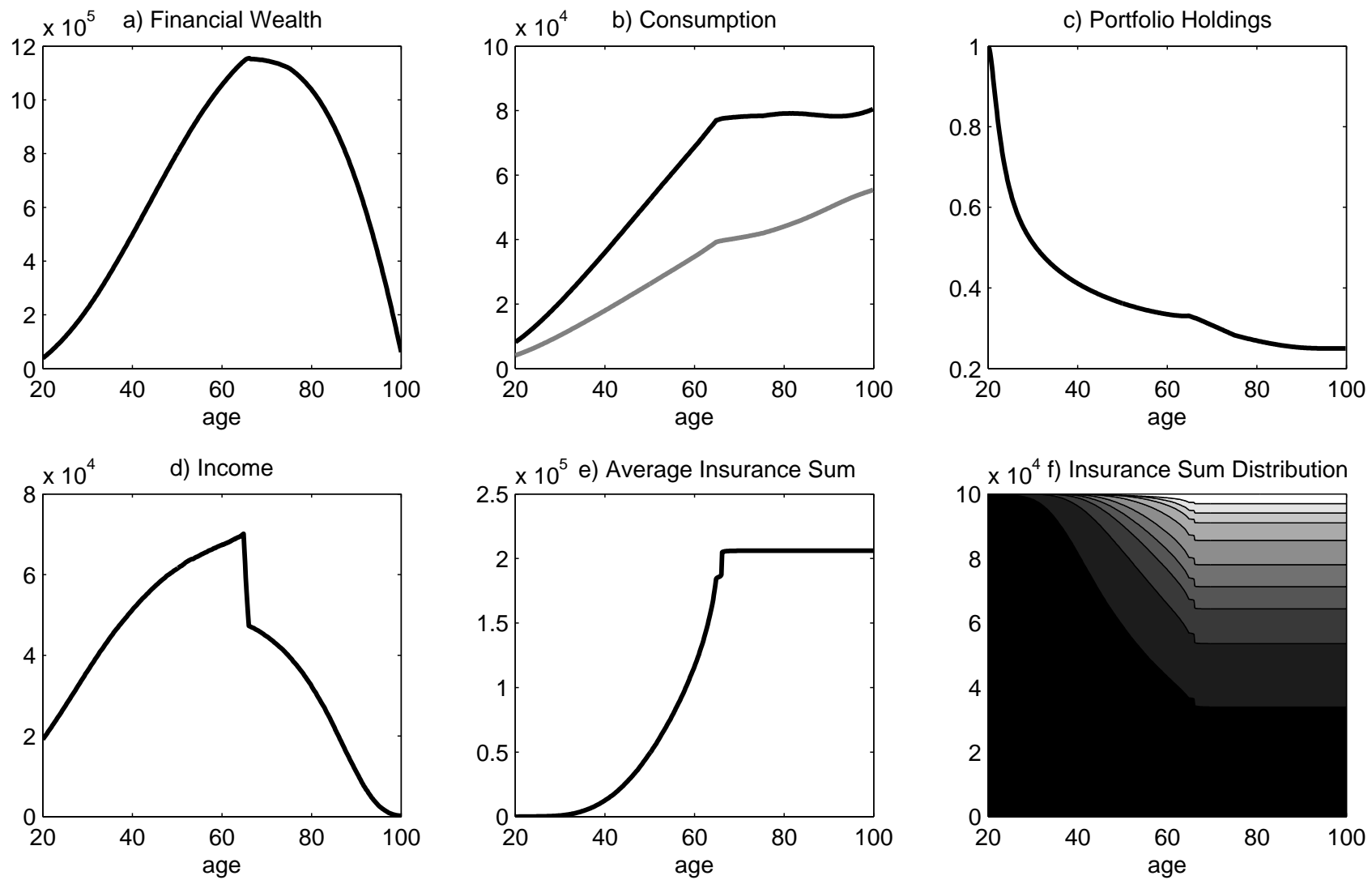

Figure 5: Average Key Variables over the Life Cycle. The graphs depict the average optimal control variables as well as the average financial wealth and income evolution over the life cycle based on 100000 simulations with the benchmark calibration of Section 4. a) shows the average financial wealth evolution over the life cycle. b) depicts the average optimal consumption over the life cycle. The dark line corresponds to the consumption of the family, whereas the grey line represents the equivalent level of consumption for a one person household and is scaled with the consumption scaling parameter $c / \phi$. c) shows the optimal average portfolio holdings over the life cycle. d) depicts the average income of the family. e) shows the average insurance sum. f) depicts the distribution of the insurance sum over the life cycle. The darkest area marks families with no insurance contract, the white area families with the highest insurance sum (2000000) and the grey areas families with intermediate insurance sums. 


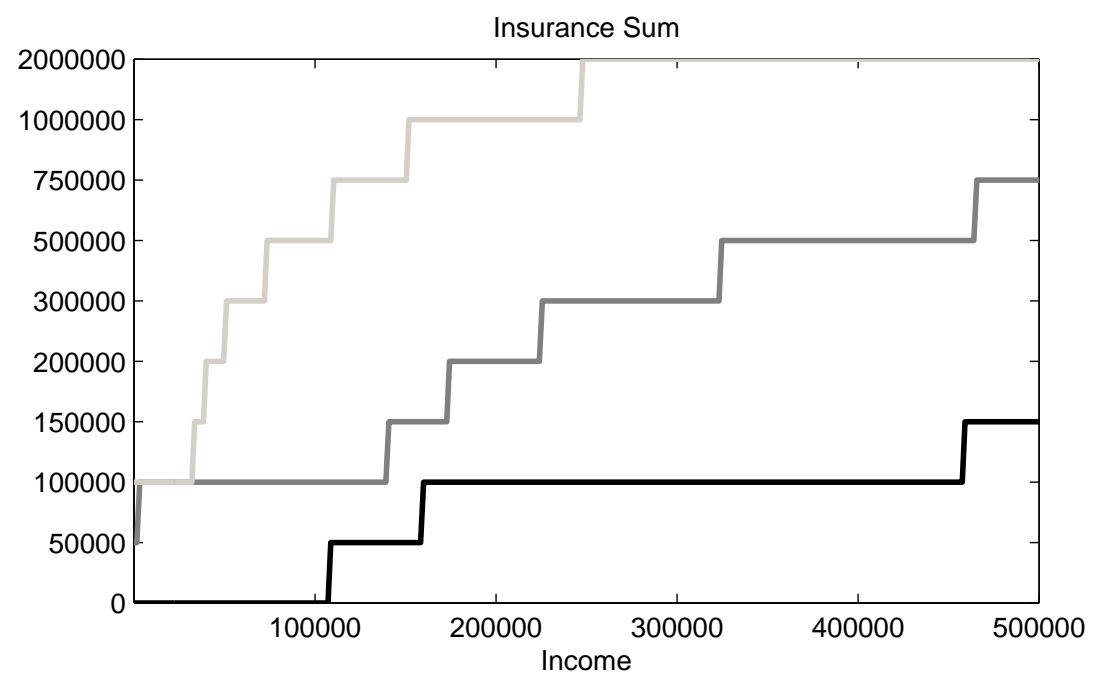

Figure 6: Insurance Demand Dependent on Income. This graph depicts the optimal insurance decision dependent on the income of a healthy agent $(A=1)$. The financial wealth is fixed to $x=800000$, the previous insurance choice is fixed to $I=100000$ and the age of the agent is fixed to 25 (dark line), 50 (grey line) and 68 (light line). The policy functions are based on the calibration presented in Section 4 .

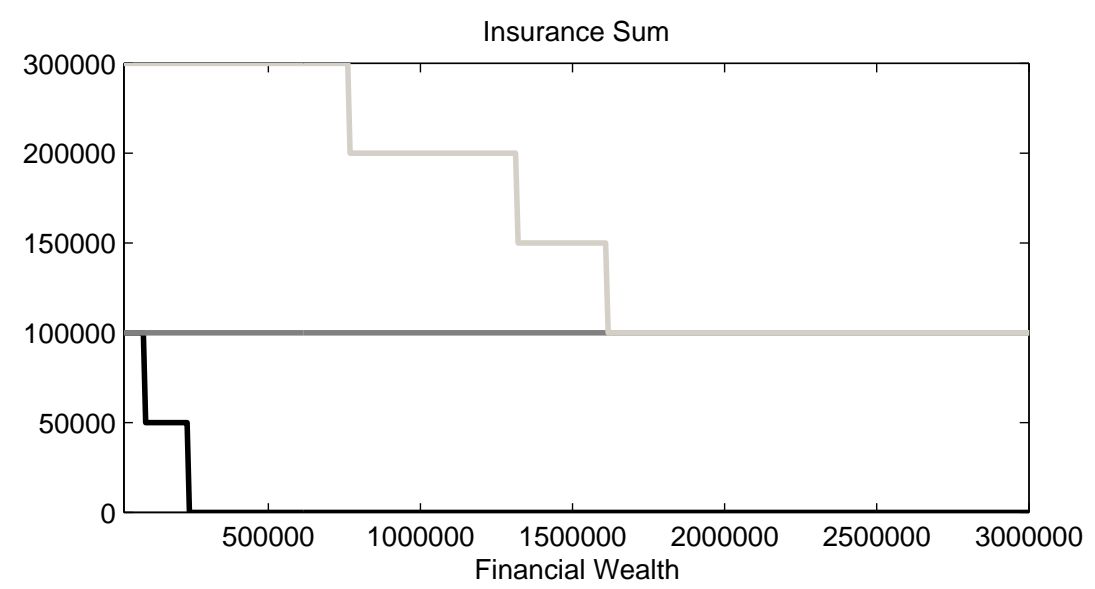

Figure 7: Insurance Demand Dependent on Financial Wealth. This graph depicts the optimal insurance decision dependent on the financial wealth of a healthy agent $(A=1)$. The income is fixed to $y=50000$, the previous insurance choice is fixed to $I=100000$ and the age of the agent is fixed to 25 (dark line), 50 (grey line) and 68 (light line). The policy functions are based on the calibration presented in Section 4. 


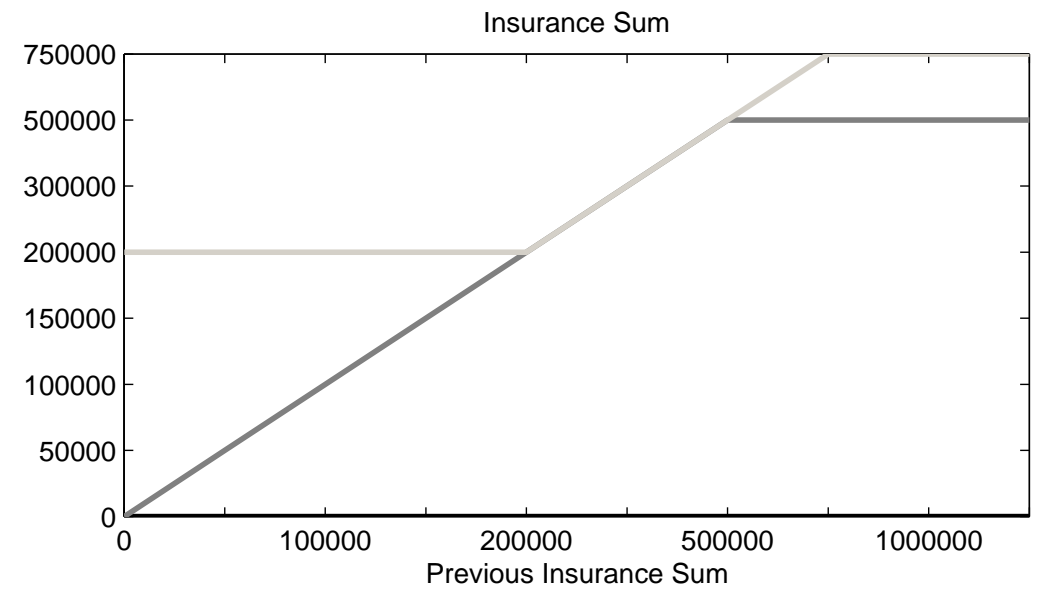

Figure 8: Insurance Demand Dependent on the Previous Insurance Sum. This graph depicts the optimal insurance decision dependent on the previous insurance sum of a healthy agent $(A=1)$. The financial wealth is fixed to $x=800000$, the income is fixed to $y=50000$ and the age of the agent is fixed to 25 (dark line), 50 (grey line) and 68 (light line). The policy functions are based on the calibration presented in Section 4. 

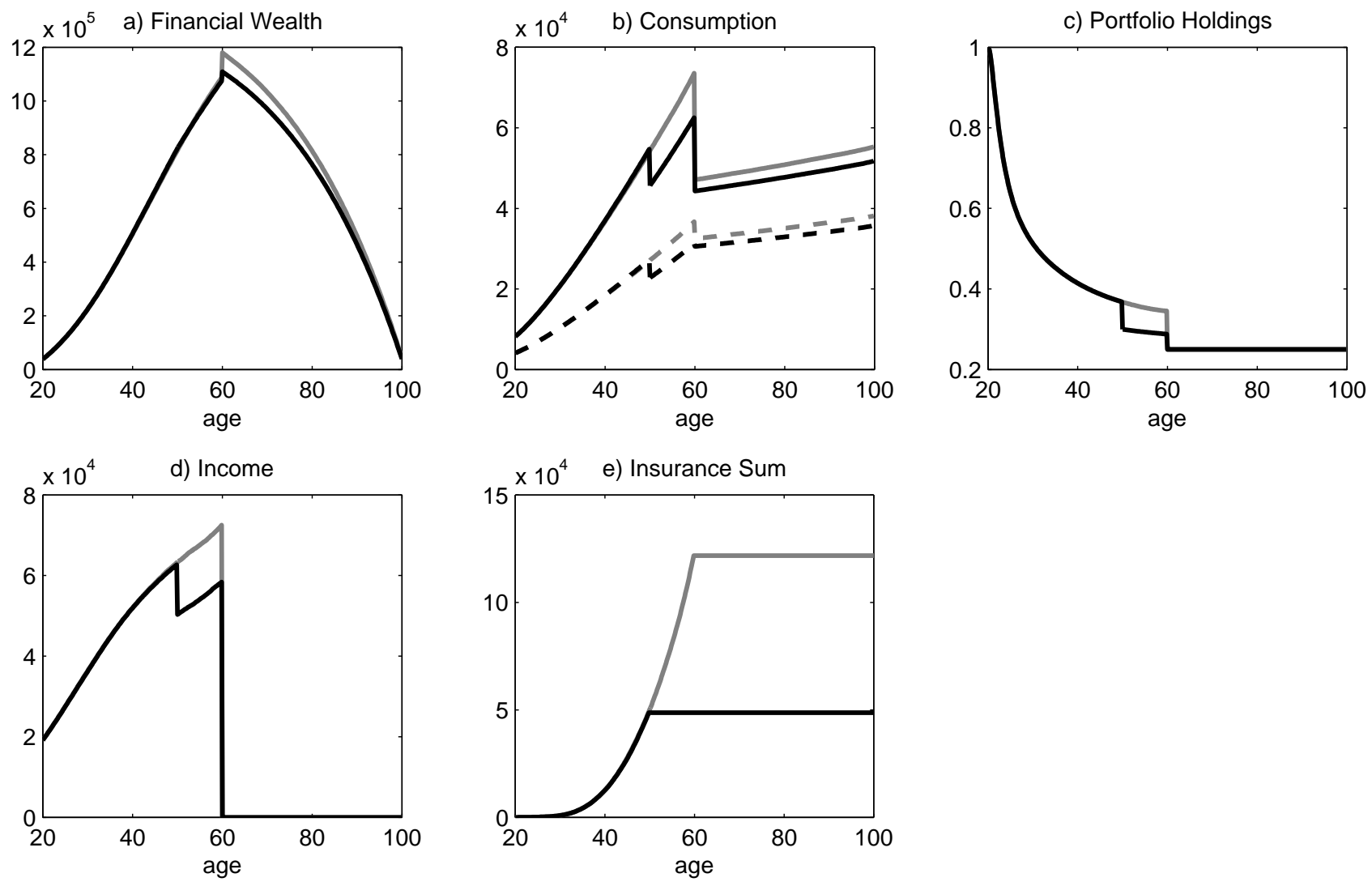

Figure 9: Optimal Reaction to Critical Illness and Death. The figure depicts the average financial wealth evolution and average optimal controls based on 100000 simulations where all wage earners are assumed to die at the age of 60 . The black lines correspond to the optimal behavior of a family where the wage earner gets a critical illness at the age of 50, whereas the grey lines represent a family whose wage earner dies without previous critical illness. The calibration equals the one of the benchmark results and is explained in Section 4. a) shows the average financial wealth evolution over the life cycle. b) depicts the average optimal consumption over the life cycle. The solid lines are for the consumption of the family $c$ and the dashed lines for the equivalent single person consumption level $c / \phi$. c) presents the average optimal portfolio holdings, d) gives the average income of the family and e) depicts the average optimal insurance sum over the life cycle. 

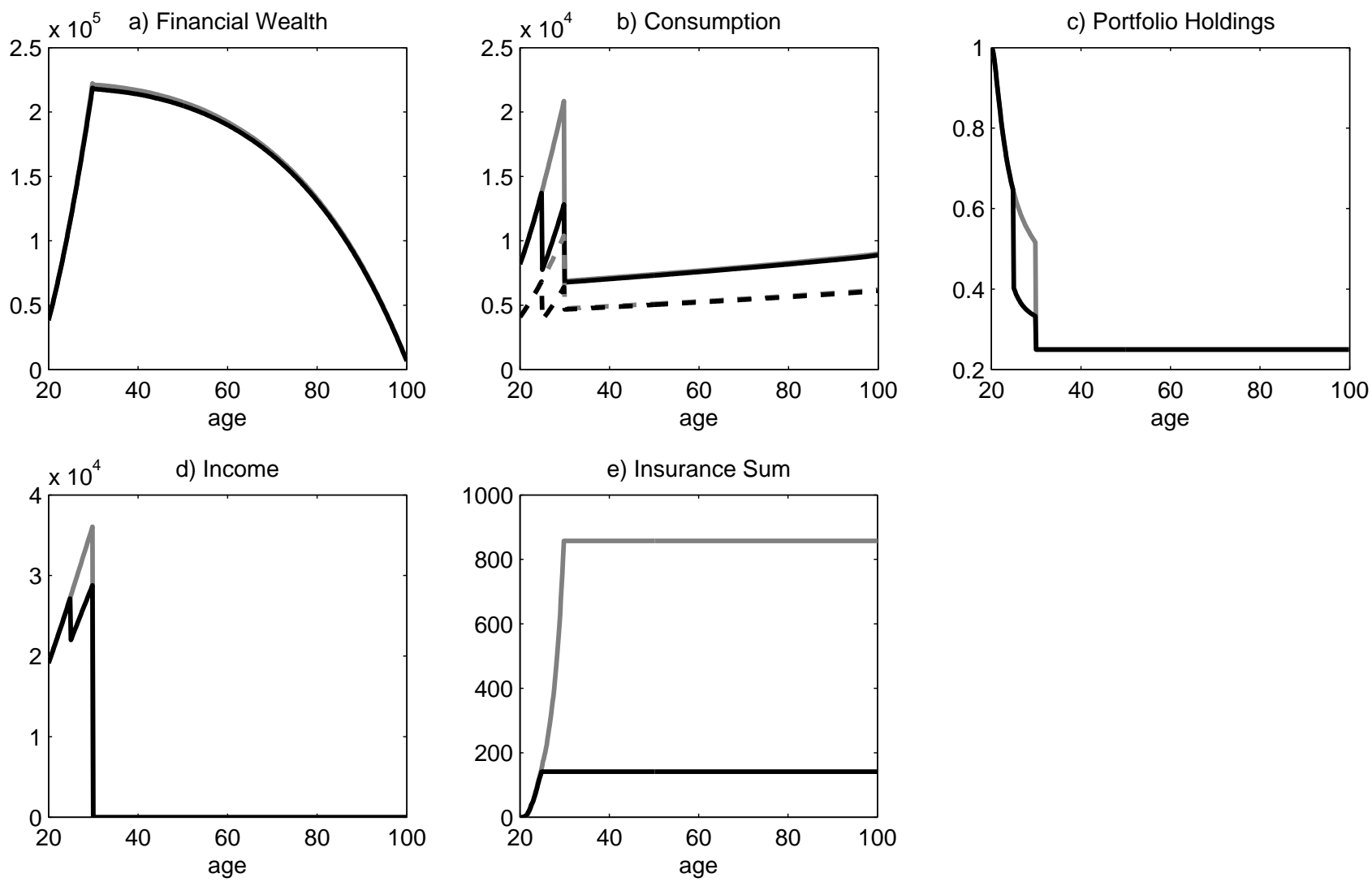

Figure 10: Optimal Reaction to Early Critical Illness and Death. The figure depicts the average financial wealth evolution and average optimal controls based on 100000 simulations where all wage earners are assumed to die at the age of 30 . The black lines correspond to the optimal behavior of a family where the wage earner gets a critical illness at the age of 25 , whereas the grey lines represent a family whose wage earner dies without previous critical illness. The calibration equals the one of the benchmark results and is explained in Section 4. a) shows the average financial wealth evolution over the life cycle. b) depicts the average optimal consumption over the life cycle. The solid lines are for the consumption of the family $c$ and the dashed lines for the equivalent single person consumption level $c / \phi$. c) presents the average optimal portfolio holdings, d) gives the average income of the family and e) depicts the average optimal insurance sum over the life cycle. 

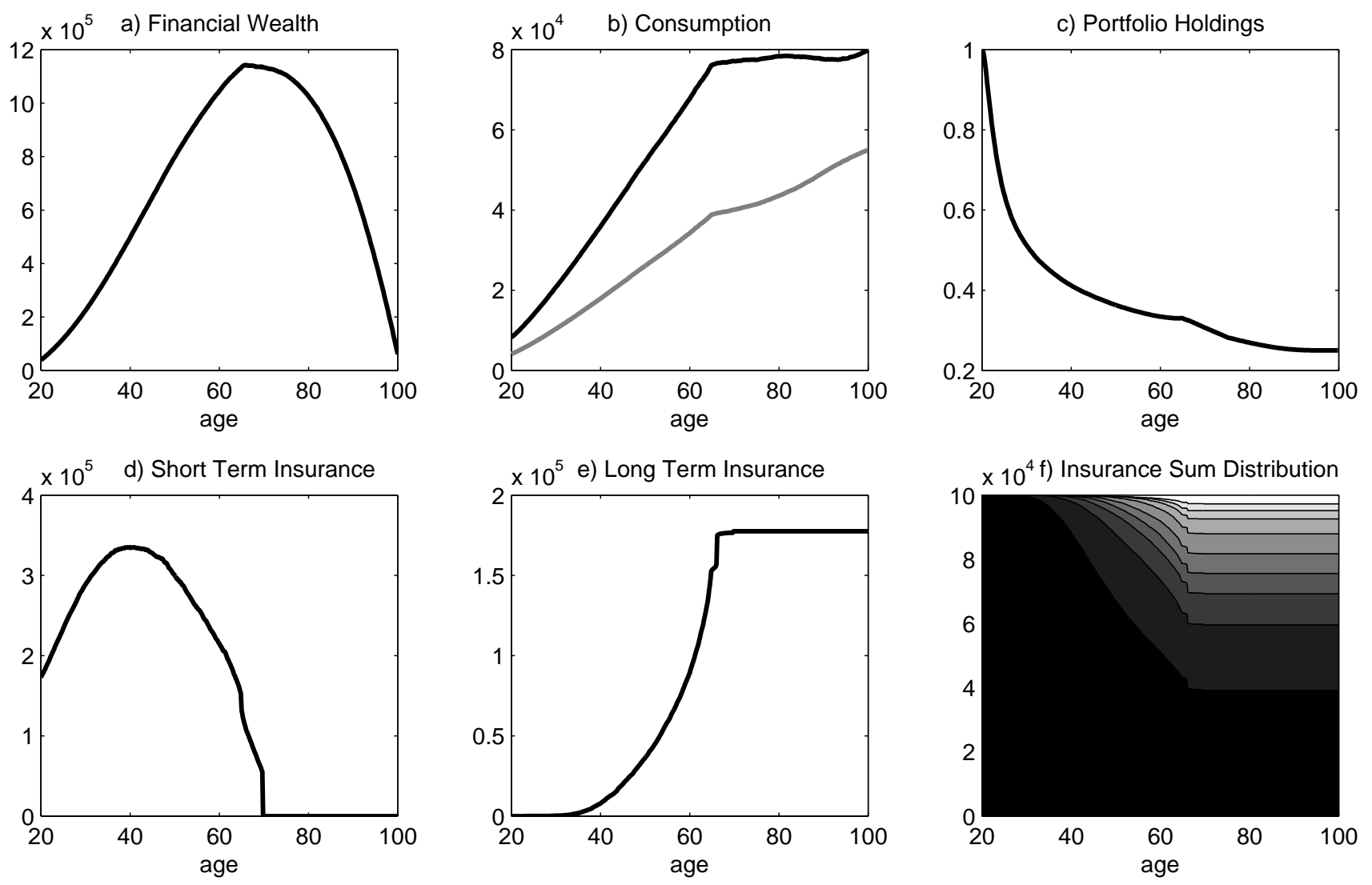

Figure 11: Average Key Variables over the Life Cycle with a Short-term Insurance Contract. This figure depicts the average optimal control variables as well as the average financial wealth and income evolution over the life cycle based on 100000 simulations. The family has access to a short-term insurance contract that are described in Section 6). a) shows the average financial wealth evolution over the life cycle. b) depicts the average optimal consumption over the life cycle. The dark line corresponds to the consumption of the family, whereas the grey line represents the equivalent level of consumption for a one person household and is scaled with the consumption scaling parameter $c / \phi$. c) shows the optimal average portfolio holdings over the life cycle. d) depicts the average short-term insurance sum. e) shows the average long-term insurance sum. f) depicts the distribution of the long-term insurance sum over the life cycle. The darkest area marks families with no insurance contract, the white area families with the highest insurance sum (2000 000) and the grey areas families with intermediate insurance sums. 


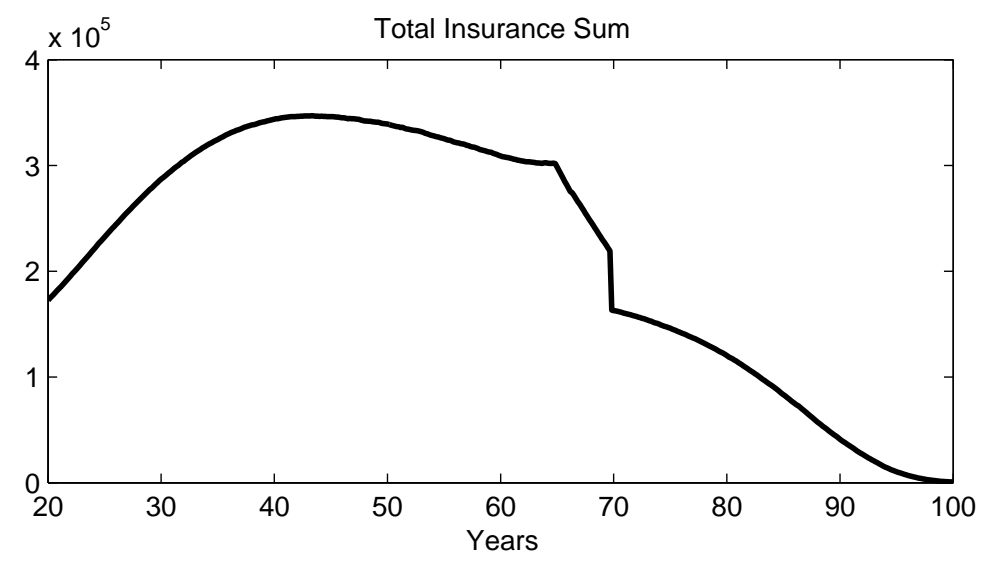

Figure 12: Total Life Insurance Holdings. This graph depicts the optimal total life insurance holdings of a wage earner that is alive. These total holdings are the sum of the short-term and long-term insurance demand. 

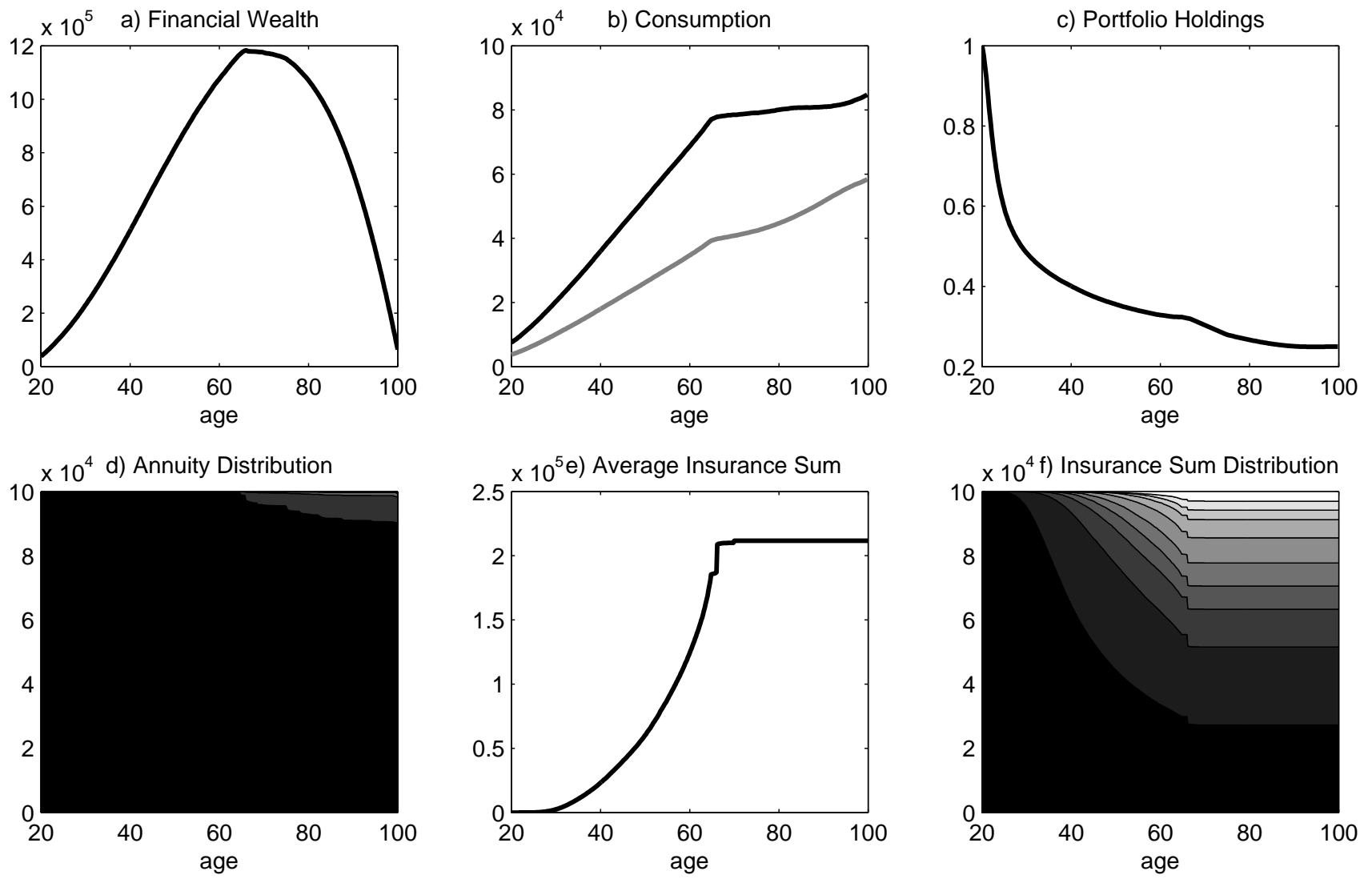

Figure 13: Average Key Variables over the Life Cycle with Annuities. This figure depicts the average optimal control variables as well as the average financial wealth and income evolution over the life cycle based on 100000 simulations. The family has access to annuities that are described in Section 6. a) shows the average financial wealth evolution over the life cycle. b) depicts the average optimal consumption over the life cycle. The dark line corresponds to the consumption of the family, whereas the grey line represents the equivalent level of consumption for a one person household and is scaled with the consumption scaling parameter $c / \phi . \quad \mathrm{c}$ ) shows the optimal average portfolio holdings over the life cycle. d) depicts the distribution of the annuities over the life cycle. The darkest area marks families with no annuity contract, the white area families with the highest insurance sum (30000) and the grey areas families with an intermediate amount of annuities. e) shows the average long-term insurance sum. f) depicts the distribution of the insurance sum over the life cycle. The darkest area marks families with no insurance contract, the white area families with the highest insurance sum (2000 000) and the grey areas families with intermediate insurance sums. 

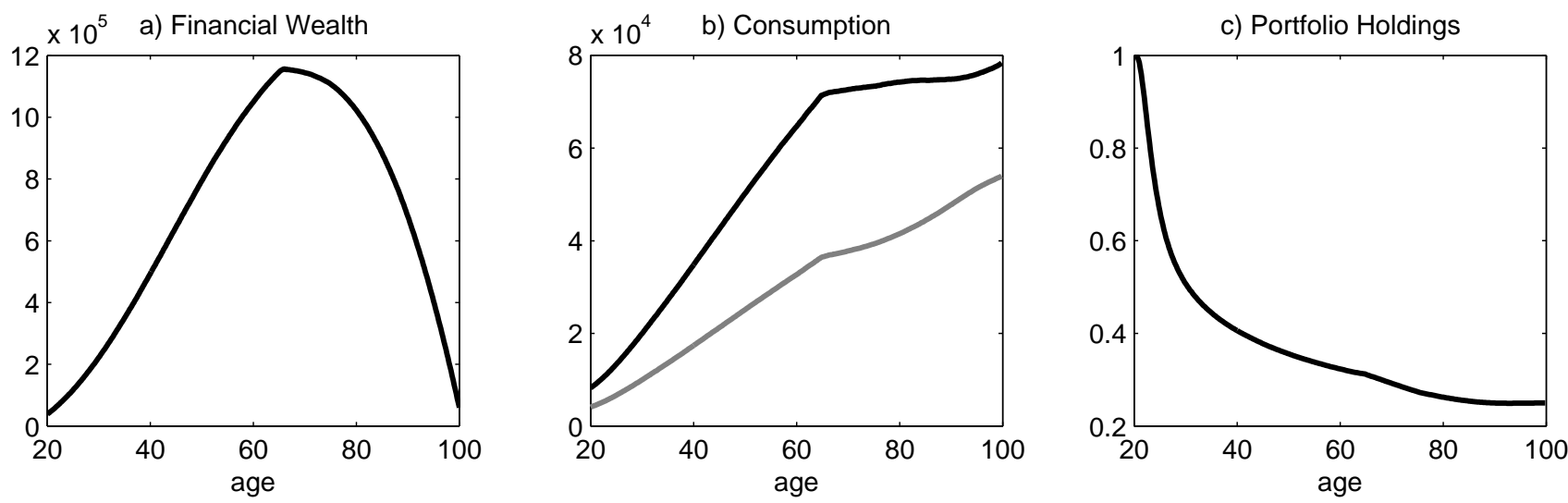

d) Health insurance
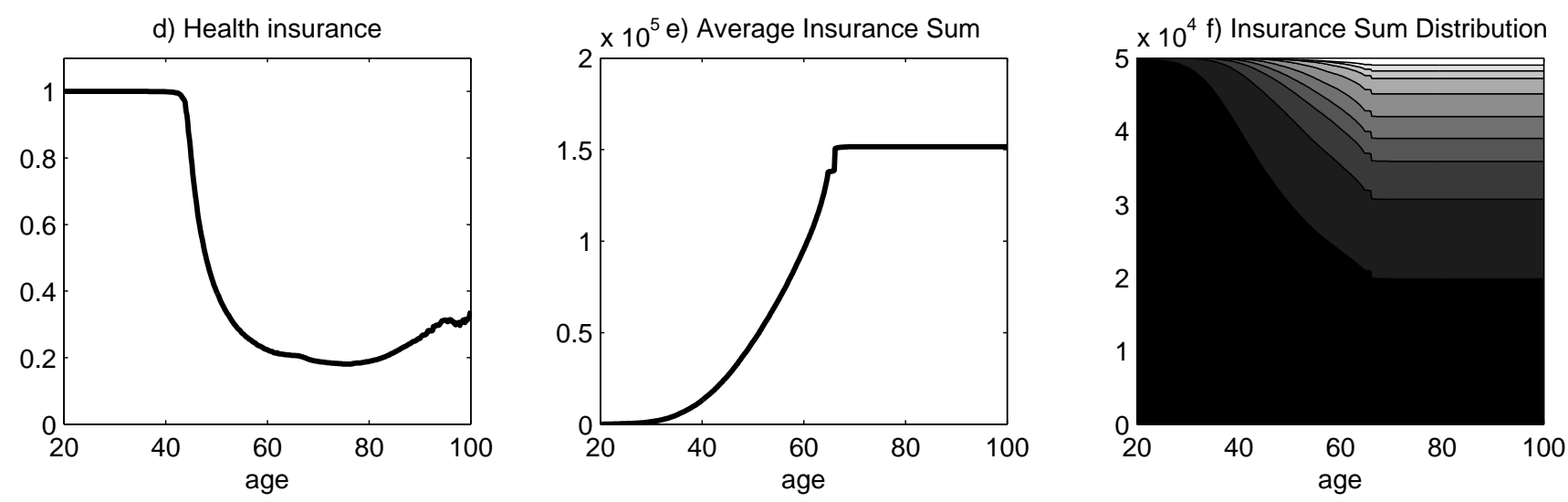

Figure 14: Average Key Variables over the Life Cycle with Health Expenses and Health Insurance. This figure depicts the average optimal control variables as well as the average financial wealth and income evolution over the life cycle based on 100000 simulations. The family has access to an additional short-term contract that is described in Section 6. a) shows the average financial wealth evolution over the life cycle. b) depicts the average optimal consumption over the life cycle. The dark line corresponds to the consumption of the family, whereas the grey line represents the equivalent level of consumption for a one person household and is scaled with the consumption scaling parameter $c / \phi$. c) shows the optimal average portfolio holdings over the life cycle. d) depicts the fraction of agents that is in the health insurance market $(H=1)$ and contracts a supplemental health insurance. e) shows the average long-term life insurance sum. f) depicts the distribution of the life insurance sum over the life cycle. The darkest area marks families with no insurance contract, the white area families with the highest insurance sum (2000 000) and the grey areas families with intermediate insurance sums. 


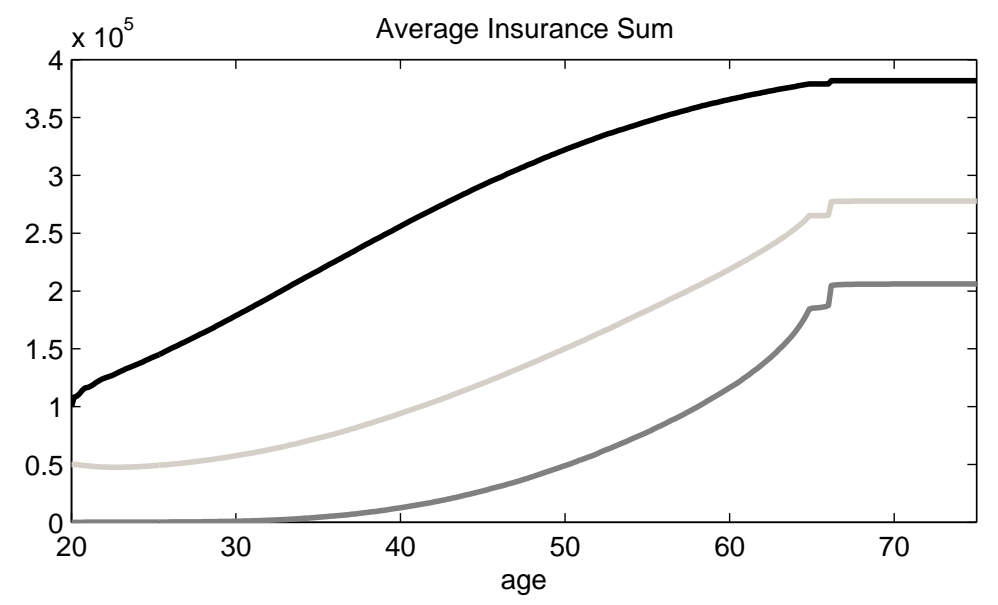

Figure 15: Insurance Demand for Different Levels of Labor Income Volatility. The dark line depicts the average insurance sum in a model where the labor income volatility before retirement is reduced to $\sigma_{Y}^{w}=0.1$ and the light line depicts a reduction to $\sigma_{Y}^{w}=0.15$. The grey line represents the benchmark results with a labor income volatility of $\sigma_{Y}^{w}=0.2$. The remaining parameters are calibrated as stated in Section 4. The results are based on 100000 simulations for each model.

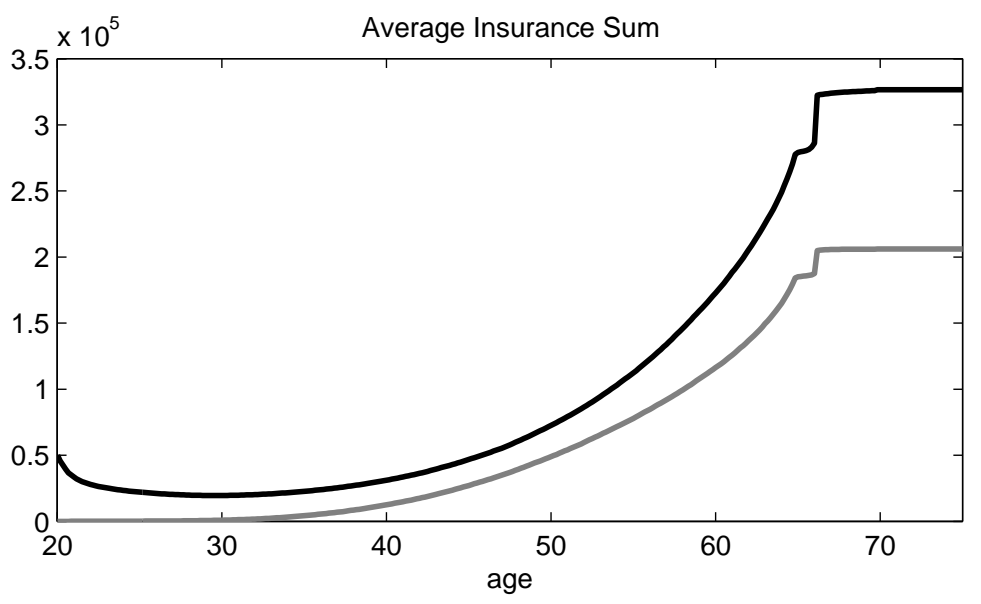

Figure 16: Insurance Demand Compared to a Model without Health Shocks. The dark line depicts the average insurance sum for a different biometric risk calibration without health shocks. Thus, the wage earner can only be in two health states $(A=1,3)$ and the family can contract and increase term life insurance contracts as long as the wage earner is alive and $t<T_{C}$. The health shock rate and magnitude are set to zero $\left(\kappa=0, k_{1}=0, k_{2}=0\right)$ and the mortality model has a standard Gompertz structure. The parameter calibration is changed to $b=8.9, m=85.47$ to get a similar death shock distribution as in the benchmark model with critical illness shocks. The grey line represents the benchmark results including health shocks and with the original mortality parameters. The remaining parameter are calibrated as stated in Section 4 . The results are based on 100000 simulations for each model. 

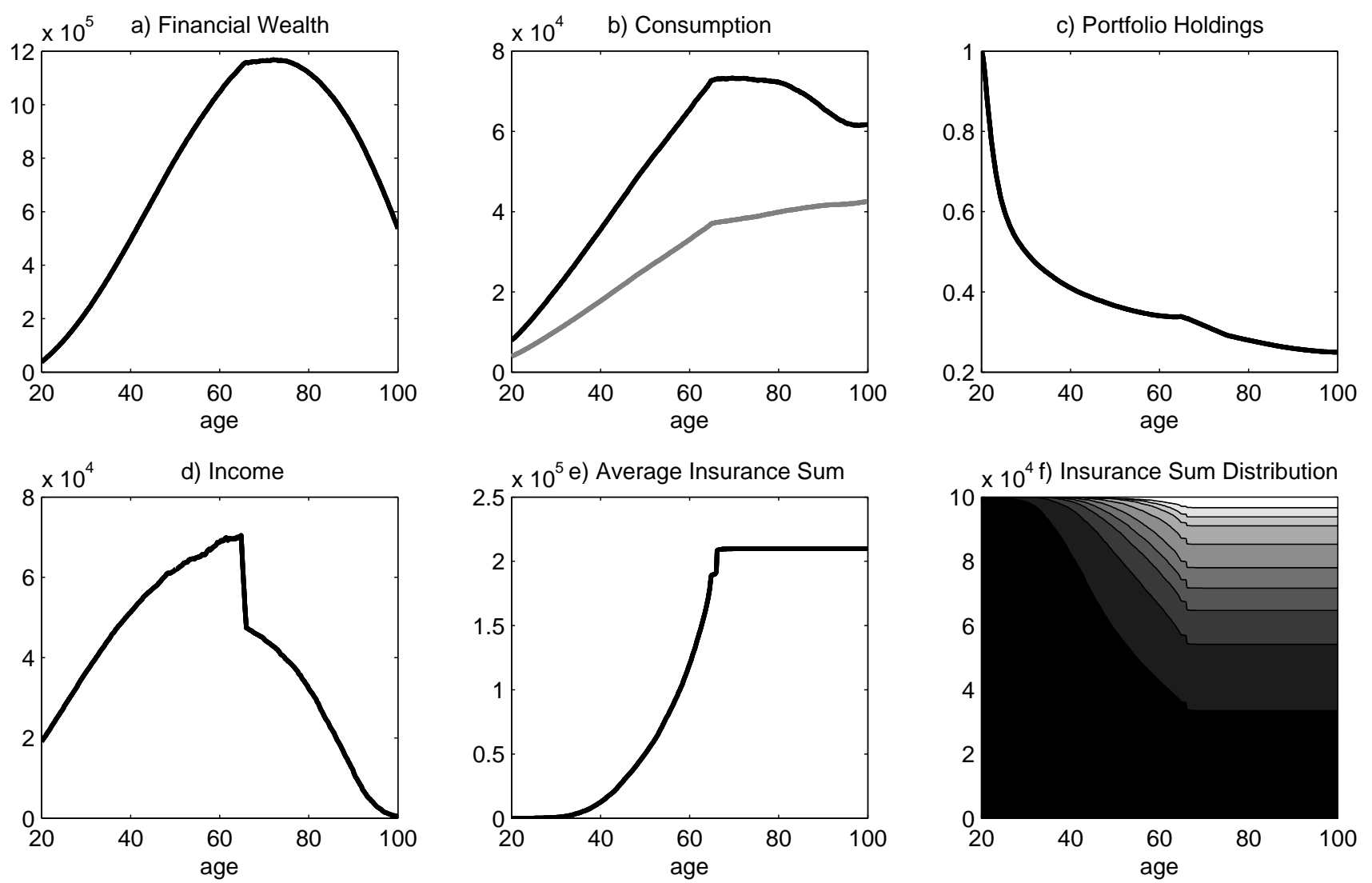

Figure 17: Average Key Variables over the Life Cycle with Bequest as Luxury Good. This figure depicts the average optimal control variables as well as the average financial wealth and income evolution over the life cycle based on 100000 simulations with luxury bequest motive. The remaining calibration is described in Section 4. a) shows the average financial wealth evolution over the life cycle. b) depicts the average optimal consumption over the life cycle. The dark line corresponds to the consumption of the family, whereas the grey line represents the equivalent level of consumption for a one person household and is scaled with the consumption scaling parameter $c / \phi$. c) shows the optimal average portfolio holdings over the life cycle. d) depicts the average income of the family. e) shows the average insurance sum. f) depicts the distribution of the insurance sum over the life cycle. The darkest area marks families with no insurance contract, the white area families with the highest insurance sum (2000 000) and the grey areas families with intermediate insurance sums. 

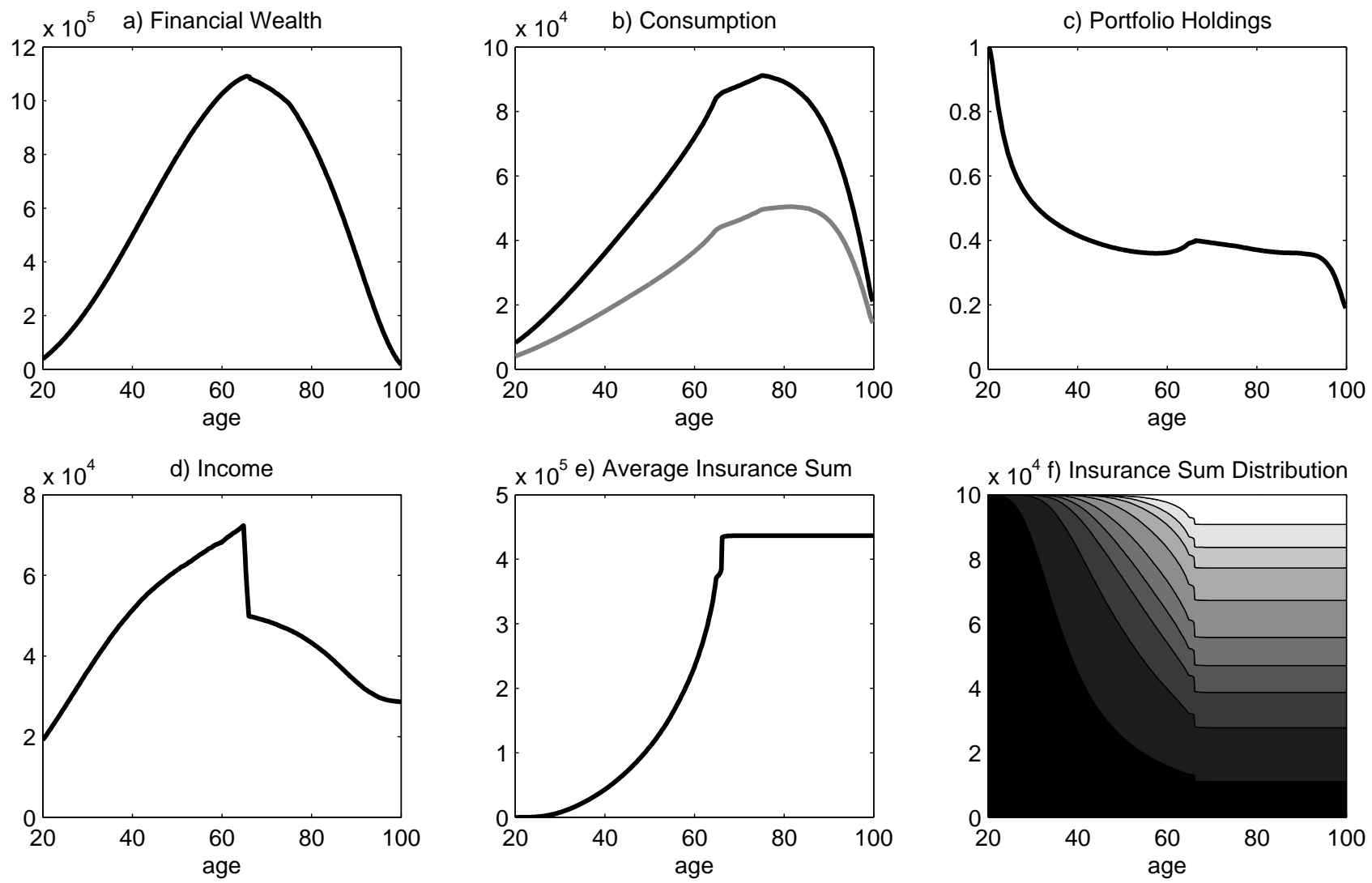

Figure 18: Average Key Variables over the Life Cycle with Social Security. The graphs depict the average optimal control variables as well as the average financial wealth and income evolution over the life cycle based on 100000 simulations with a social security system as given in (7.5). The remaining calibration is described in Section 4. a) shows the average financial wealth evolution over the life cycle. b) depicts the average optimal consumption over the life cycle. The dark line corresponds to the consumption of the family, whereas the grey line represents the equivalent level of consumption for a one person household and is scaled with the consumption scaling parameter $c / \phi$. c) shows the optimal average portfolio holdings over the life cycle. d) depicts the average income of the family. e) shows the average insurance sum. f) depicts the distribution of the insurance sum over the life cycle. The darkest area marks families with no insurance contract, the white area families with the highest insurance sum (2000 000) and the grey areas families with intermediate insurance sums. 


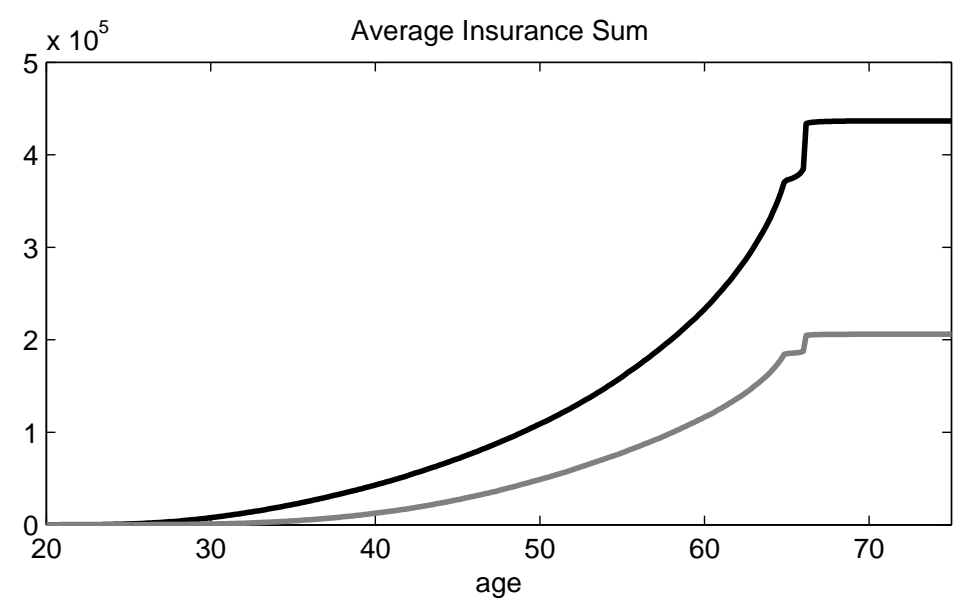

Figure 19: Insurance Demand with Social Security System. The figure depicts the average insurance sum over the life cycle for a different income reduction at death $p^{1,3}, p^{2,3}$. The dark line presents results of a model with social security system as given in (7.5). The grey line corresponds to the benchmark results without social security system $p^{1,3}=p^{2,3}=0$. The remaining parameter are calibrated as stated in Section 4. The results are based on 100000 simulations for each model.

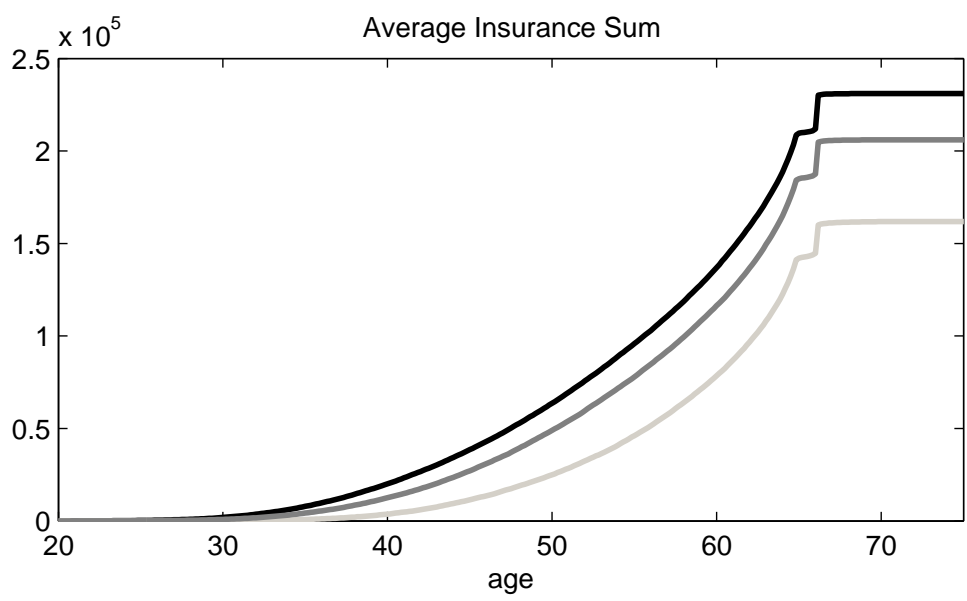

Figure 20: Insurance Demand for Different Fees. The light line depicts the average insurance sum in a model where the fees of the insurance company are increased such that the administrative fee is $\psi_{a d}=12.68 \%$ and the transaction fee equals $\psi_{t r}=13.62 \%$. The values are taken from "map-report no. 807-808" and represent the highest fees in the German life insurance market. The dark line is for an actuarially fair insurance without fees $\left(\psi_{a d}=0, \psi_{t r}=0\right)$. The grey line represents the benchmark results with fees of $\psi_{a d}=2.99 \%$ and $\psi_{t r}=5.05 \%$ that correspond to average fees in the German life insurance market. The remaining parameter are calibrated as stated in Section 4. The results are based on 100000 simulations for each model. 


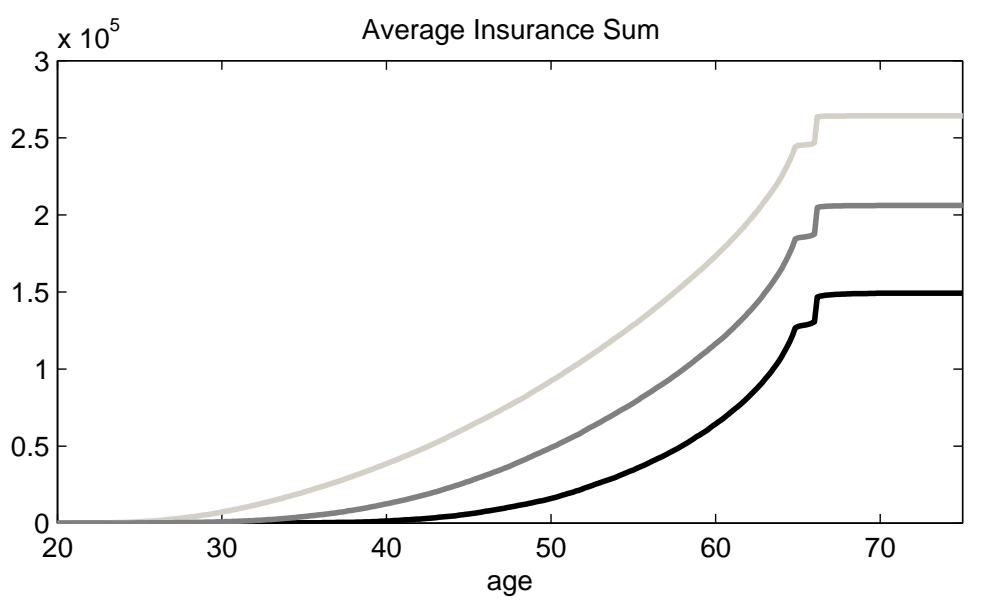

Figure 21: Insurance Demand for Different Family Sizes. The dark line depicts the average insurance sum over the life cycle for a family without children. The consumption scaling parameter are changed to $\phi_{1,2}=1.6245$ and $\phi_{3}=1$. The light line gives the insurance demand with three children and the corresponding parameters are $\phi_{1,2}=2.6850, \phi_{3}=2.2078$. The grey line represents the benchmark results for a family with one child and consumption scaling parameters are $\phi_{1,2}=2.0043$ and $\phi_{3}=1.4498$. The remaining parameter are calibrated as stated in Section 4. The results are based on 100000 simulations for each model.

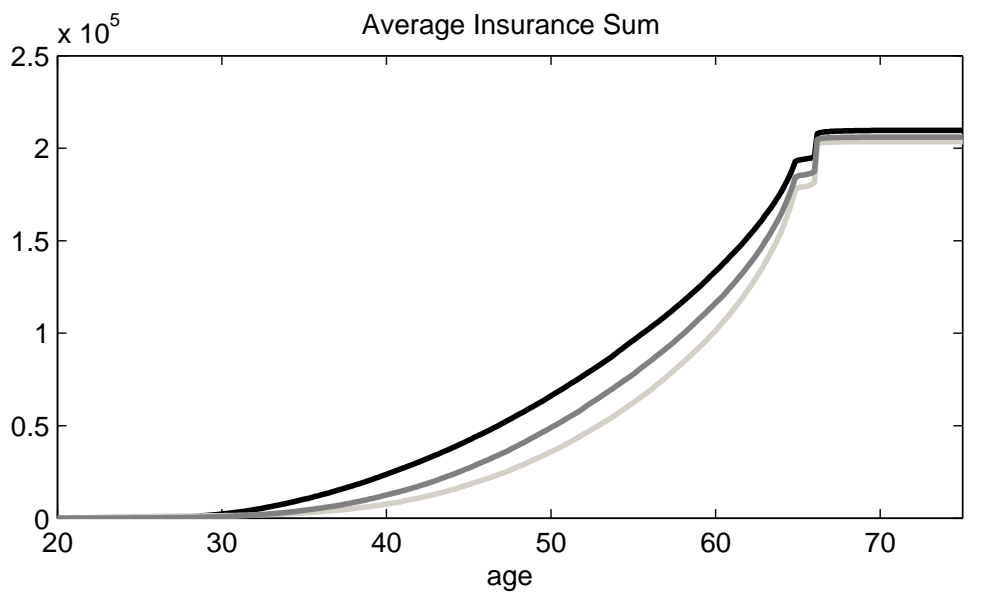

Figure 22: Insurance Demand for Different Risk Aversions. The figure depicts the average insurance sum over the life cycle for different values of the relative risk aversion. The dark line shows results for a low level of relative risk aversion $(\gamma=3)$, the grey line corresponds to the benchmark case with $\gamma=4$ and the light line presents a more risk averse agent with $\gamma=5$. The remaining parameters are calibrated as stated in Section 4. The results are based on 100000 simulations for each model. 